REVISTA DE DERECHO UNED, NÚM. 23, 2018

\title{
¿MUJER, PLURALISMO RELIGIOSO E IGUALDAD DE GÉNERO?: DESAFÍO JURÍDICO EN EL SIGLO XXI EN ESPAÑA
}

\author{
WOMAN, RELIGIOUS PLURALISM AND GENDER EQUALITY?: \\ LEGAL CHALLENGE IN THE 21ST CENTURY IN SPAIN
}

\author{
Premio de Artículos Jurídicos «García Goyena» \\ XVII Edición \\ Segundo accésit
}

María José Parejo GuZMÁN

\begin{abstract}
Resumen: Resultando evidentes las desigualdades por razón de sexo existentes en el ámbito del fenómeno religioso dentro y fuera de nuestras fronteras, se antoja sobradamente interesante afrontar el desafío jurídico de estudiar, en el contexto de la diversidad religiosa, el papel de la mujer y su posible discriminación o no en dicho ámbito en nuestra España del siglo XXI. Dentro de la inmensa dimensión que abarca el referido fenómeno, nos centraremos en los conflictos en los que sean parte los intereses de la mujer cuando se desarrollen en el ámbito de las principales confesiones con arraigo en nuestro país. El objetivo principal de este estudio ha sido describir los más importantes conflictos acaecidos y en los que se observa discriminación de la mujer en el ámbito religioso, a saber, principalmente el debate suscitado en torno al porte del velo islámico, pero también otras posibles discriminaciones en el ámbito religioso: los delitos de odio por razón de género en el ámbito religioso, el acceso a los puestos de autoridad eclesiástica por parte de las mujeres en las distintas confesiones religiosas, la mutilación genital femenina..., dejando palpable la necesaria exigencia de
\end{abstract}


igualdad de género que consideramos debería existir en el ámbito de la diversidad religiosa. Finalmente, vamos a plantear en este estudio aquello que, a nuestro entender, puede ser exigible a los Estados, y más concretamente al Estado español, para garantizar la universalidad de los derechos de las mujeres en el marco de las religiones.

Palabras clave: Mujer, discriminación, igualdad de género, ámbito religioso, velo islámico.

Abstract: Being evident the inequalities by reason of sex existing in the scope of the religious phenomenon inside and outside our borders, it seems very interesting to face the legal challenge of studying, in the context of religious diversity, the role of women and their possible discrimination or not in this area in our Spain of the XXI Century. Within the immense dimension encompassed by this phenomenon, we will focus on the conflicts in which the interests of women are part when they develop within the scope of the main confessions rooted in our country. The main objective of this study has been to describe the most important conflicts that have occurred and in which there is discrimination against women in the religious sphere, namely, mainly the debate about the wearing of the Islamic headscarf, but also other possible discriminations in the religious sphere: hate crimes on the grounds of gender in the religious sphere, access to positions of ecclesiastical authority by women in different religious confessions, female genital mutilation ..., leaving palpable the necessary requirement of equality of gender that we believe should exist in the area of religious diversity. Finally, we will propose in this study that which, in our opinion, may be required from the States, and more specifically from the Spanish State, to guarantee the universality of women's rights within the framework of religions.

Keywords: Woman, discrimination, gender equality, religious sphere, islamic headscarf.

Sumario: I. Introducción.-II. El estado de la cuestión: II.1. Modelo de Estado actual e influencia del preconstitucional; Pluralismo religioso. II.2. Marco jurídico: a) Relaciones EstadoConfesiones; b) Principios y derechos reconocidos: - libertad religiosa; —igualdad; —laicidad y cooperación.-III. Mujer y religión: III.1. Retomando el multiculturalismo a propósito de su influencia en la mujer; III.2. Perspectivas generales de la mujer en la religión: a) justificación de la violencia y discriminación por motivos religiosos; b) rol de la mujer a causa de la religión; III.3. Perspectivas 
particulares de la mujer en cada confesión: a) catolicismo; b) Evangelismo; c) Confesión islámica; d) judaísmo.-IV. Velo Islámico: IV.1. Velo: origen, concepto y tipos; IV.2. Estado actual de la cuestión en España desde el punto de vista normativo; IV.3. Jurisprudencia española en torno al velo islámico.-V. Distintas posibles discriminaciones en el ámbito religioso: V.1. Delitos de odio por razón de género en el ámbito religioso; V.2. Acceso a los puestos de autoridad eclesiástica en las distintas confesiones; V.3. La mutilación genital femenina.-VI. Conclusiones a la vista de las soluciones doctrinales y jurisprudenciales analizadas.-VII. Bibliografía utilizada.

\section{INTRODUCCIÓN}

El viejo aforismo romano señala que «Donde hay sociedad hay Derecho» (Ubi societas, ibi ius). Esto deviene de la necesidad de proteger los intereses contrapuestos de los individuos que integran la sociedad que se pretende ordenar. La contraposición de esos intereses es la génesis de todo conflicto al que el ordenamiento jurídico se enfrenta para dar la solución más justa. No obstante, la noción de justicia queda vinculada al contexto en el que se desarrollen, interpreten y apliquen las normas jurídicas que ansían la tutela de los intereses en conflicto.

Partiendo de esta premisa, se pretende en este trabajo analizar la tutela otorgada a unos determinados intereses, los relativos a la figura de la mujer, contextualizados, a su vez, en un concreto marco cual es el fenómeno religioso. Es decir, analizar el papel que juega la mujer en el ámbito religioso, tratando para ello de plasmar una visión general de los factores que pueden influir en ese papel para, posteriormente, poner de manifiesto el rol del género femenino en cada una de las distintas confesiones.

Según veremos, se viene comprobando desde hace tiempo lo interesante que resulta estudiar la evidente concepción de desigualdad que existe entre géneros construida a partir de argumentos sociales, culturales y religiosos. Pues bien, en este trabajo nos centraremos en plantear, más concretamente, la perspectiva «religión e igualdad de género», es decir, cuál es la situación actual de los derechos de las mujeres en las distintas confesiones religiosas. Es decir, vamos a estudiar la situación de las sociedades en la actualidad en las que, cada vez más a menudo, la discriminación de la mujer en el marco de las religiones se hace palpable a la vez que ciertamente injusto y 
delictivo. El objetivo de este estudio ha sido tratar de profundizar, en libertad, en aquellos aspectos relacionados con la igualdad de género en el ámbito de las religiones y de su influencia en la sociedad, proponiendo desde una España laica como la nuestra no dar ni un paso atrás en los derechos conquistados y exigir los que faltan por conquistar.

Tras empezar contextualizando el papel que desarrolla la mujer en el ámbito religioso, pasaremos a centrar nuestra atención en la cuestión que más debate ha venido suscitando desde hace unos años en el ámbito que estamos analizando, a saber, la utilización del conocido velo islámico. Vamos así a describir lo poco o lo mucho que nos permitan nuestras limitaciones de espacio sobre el estado actual de la cuestión del porte del velo islámico, doctrinal y jurisprudencialmente, como importantísimo desafío jurídico que es, en nuestra España del presente siglo XXI. Posteriormente, vamos a pasar a analizar otras distintas y también importantes posibles discriminaciones de la mujer que existen en el ámbito del pluralismo religioso, a saber, los delitos de odio por razón de género en el ámbito religioso, el acceso a los puesto de autoridad eclesiástica por parte de las mujeres en las distintas confesiones religiosas, la mutilación genital femenina... Para terminar, vamos a plantear aquello que, a nuestro entender, pueda ser exigible a los Estados, y más concretamente al Estado español, para garantizar la universalidad de los derechos de las mujeres en el marco de las religiones.

\section{EL ESTADO DE LA CUESTIÓN}

Antes de entrar de lleno en la problemática fundamental y principal objeto de este estudio vamos a empezar tratando de dibujar de una forma muy básica y elemental el marco que contextualiza la práctica de las distintas confesiones, así como, los derechos y principios que informan tales prácticas, es decir, el marco jurídico del actual pluralismo religioso.

\section{II.1. Modelo de Estado actual e influencia del preconstitucional; pluralismo religioso}

La entrada en vigor de la Constitución española (CE) supuso la conversión de nuestro país en un Estado democrático y de Derecho, 
provocando, con ello, importantes cambios en las relaciones Estado español-confesiones religiosas. Así, la vigente concepción de nuestro Estado en relación con su postura ante el fenómeno religioso es la de Estado laico. En efecto, en esta línea, CONTRERAS MAZARIO ${ }^{1}$ clasifica a nuestro Estado bajo un modelo de separación entre el poder político y el poder religioso, en contraposición de aquellos modelos que denomina de unión y bajo los que engloba a «todo Estado que sostiene una particular religión». No debemos perder de vista la distinción que realiza el autor si se pretende contextualizar con rigor el objeto que aquí se analiza y ello por cuanto que la historia contemporánea de España se sustentó en un modelo de corte confesional, excepción hecha al corto periodo republicano cuya visión del fenómeno religioso podemos considerar, según el autor, como laicista.

Conviene pues precisar el matiz diferenciador entre el tratamiento preconstitucional del fenómeno religioso, bajo un modelo en el que se produce una identificación y vinculación del Estado con unas determinadas creencias religiosas, las católicas, del modelo coetáneo al periodo constitucional, concebido en su artículo 16 como aconfesional. Para ser más precisos nos referiremos a Estado laico como aquél que, pese a tratarse de un modelo separatista del fenómeno religioso, realiza una valoración positiva de la actividad estrictamente religiosa, posicionándose como neutral, pero sin perder de vista la necesaria coordinación o colaboración con las distintas confesiones para alcanzar sus objetivos ${ }^{2}$.

Lo relevante es poner el acento en la fuerte influencia que sobre nuestro ordenamiento jurídico presentaba la Iglesia católica en el periodo preconstitucional como acabamos de señalar. Ello se sustentaba en un profundo arraigo social de la confesión católica en nuestras costumbres, lo cual afectaba, sin lugar a dudas, a la posición que ocupaba la mujer en el ámbito familiar y social. No debemos perder de vista este contexto del que venimos, toda vez que, por desgracia, aún quedan restos de las ideas más conservadoras que son causa de conflictos a distintos niveles, como tendremos ocasión de ver.

Otro elemento a tener en cuenta para contextualizar el entorno jurídico-religioso en el que nos movemos es el fenómeno migratorio, lo cual produce un incremento de la población perteneciente a distintas confesiones, originando con ello un multiculturalismo y una

${ }^{1}$ CONTRERAS MAZARÍO, J., Derecho y Factor Religioso, Valencia, Tirant lo Blanch, 1. a ed., 2015, p. 17.

${ }^{2}$ Cfr. CONTRERAS MAZARÍO, J., Derecho y Factor Religioso (cit.), p. 17.

(C) UNED. Revista de Derecho UNED, núm. 23, 2018 
sociedad plural en lo religioso con el que hay que lidiar para la resolución de nuevos conflictos. El fenómeno migratorio, con su consiguiente incremento de la multiculturalidad y el pluralismo religioso, está presente en las políticas de la Unión Europea (UE) de forma que las instituciones comunitarias abogan por la integración ${ }^{3}$.

Al respecto, señala GARCÍA VÁZQUEZ que la UE tiene presente una serie de valores básicos integrantes de la cultura jurídica occidental y que, en todo caso, son innegociables y deben ser respetados por ciudadanos originarios de los Estados miembros y personas que deseen establecerse temporal o definitivamente en el territorio de la $\mathrm{UE}^{4}$. Más adelante retomaremos esta cuestión para observar cómo esta variable del pluralismo religioso, afecta al terreno de la mujer. Ahora nos basta con adelantar que el pluralismo debe limitarse para no acudir a las especificidades culturales y/o religiosas como justificación para violar los derechos de las mujeres ${ }^{5}$.

En definitiva, las dos variables que hemos considerado para contextualizar el fenómeno religioso en nuestro país, laicidad y pluralismo religioso, tienen su inevitable punto de conexión en la libertad religiosa (vid. Infra). Frecuentemente, nos encontramos con conflictos en los que se relacionan las costumbres de nuestra sociedad con las de determinadas confesiones, siendo ejemplo paradigmático de ello el rechazo del velo islámico por un sector generalizado de la sociedad.

\section{II.2. Marco jurídico}

A continuación, haremos una breve referencia, formal y de fondo, a las normas jurídicas que regulan actualmente la cuestión objeto de estudio. Eso sí, destacar que el ánimo del presente apartado es que el lector tenga en mente la influencia que el marco regulador del fenómeno religioso tiene sobre la cuestión femenina, por lo que, no perdiendo de vista esta cuestión, haremos referencia con-

${ }^{3}$ Concepto que, según el Plan Estratégico de Ciudadanía e integración 20072010 (Plan Estratégico de Ciudadanía e Integración 2007-2010, Madrid, Ministerio de Trabajo y Asuntos Sociales, 2007, p. 26), es entendido en el seno de la UE como "proceso bidireccional y dinámico de ajuste mutuo por parte de todos los inmigrantes y residentes de los Estados miembros con el ineludible respeto de los valores básicos de la Unión Europea».

${ }^{4}$ GARCÍA VÁZQUEZ, S., El derecho a la libertad religiosa y el uso del velo islámico. Marco constitucional, normativo y Jurisprudencial, 2013, p. 394.

5 SALAZAR BENÍTEZ, O., La autonomía relacional de las mujeres como límite de la diversidad cultural y religiosa: A propósito de la polémica prohibición del velo integral, 2015, pp. 28 y ss. 
tinua a cómo puede afectar la actual regulación al papel que pueda desarrollar la mujer, remitiéndonos, en su caso, a epígrafes posteriores en los que trataremos la resolución judicial de conflictos similares. Pondremos especial énfasis en los límites previstos en el ejercicio de la libertad religiosa, pues estos afectan especialmente, como veremos, a nuestro objeto de estudio.

\section{a) Relaciones Estado-Confesiones}

Aludíamos anteriormente a la importancia de contextualizar el problema al que nos enfrentamos, para lo cual, si queremos dar respuesta a los conflictos desde el punto de vista jurídico debemos tener en mente las fuentes que integran las relaciones jurídico-religiosas.

Como decíamos, la CE de 1978 supuso un importante cambio en las relaciones con el fenómeno religioso, considerando CONTRERAS MAZARÍO que «supuso un profundo proceso de renovación del ordenamiento jurídico con el fin de acomodarlo a la nueva configuración de España como un Estado social y democrático de Derecho»"${ }^{6}$. En efecto, se pasó de la anterior confesionalidad católica a un sistema institucional inspirado por cuatro principios fundamentales: libertad religiosa de personas y confesiones, neutralidad del Estado en materia religiosa, igualdad ante la ley y cooperación del Estado con las Iglesias y Comunidades Religiosas, principios que se encuentras recogidos en los artículos 16 y $14 \mathrm{CE}$. La nueva regulación de este nuevo sistema se desarrolló por la Ley Orgánica de Libertad Religiosa (LOLR), cuyos artículos 5 a 8 establecen las pautas esenciales a tener presentes en las relaciones Estado-Confesiones religiosas. En concreto nos interesa especialmente el artículo 7, en virtud del cual se desarrollaron acuerdos o convenios de cooperación entre el Estado y las Confesiones religiosas que alcancen notorio arraigo ${ }^{7}$ en

${ }^{6}$ CONTRERAS MAZARÍO, J., Derecho y Factor Religioso (cit.), p. 45.

${ }^{7}$ Con ánimo de aportar seguridad jurídica al concepto de «notorio arraigo»se elabora el Real Decreto 593/2015, que establece los criterios a tener en cuenta para considerar a una determinada confesión como notoriamente arraigada, a saber: «a) Llevar inscritas en el Registro de Entidades Religiosas treinta años, salvo que la entidad acredite un reconocimiento en el extranjero de, al menos, sesenta años de antigüedad y lleve inscrita en el citado Registro durante un periodo de quince años. b) Acreditar su presencia en, al menos, diez Comunidades Autónomas y/o Ciudades de Ceuta y Melilla. c) Tener 100 inscripciones o anotaciones en el Registro de Entidades Religiosas, entre entes inscribibles y lugares de culto, o un número inferior cuando se trate de entidades o lugares de culto de especial relevancia por su actividad y número de miembros. d) Contar con una estructura y representación adecuada y suficiente para su organización a los efectos de la declaración de notorio arraigo. e) Acreditar su presencia y participación activa en la sociedad española».

(C) UNED. Revista de Derecho UNED, núm. 23, 2018 
nuestro país. De este modo, el sistema jurídico-religioso vigente se fundamenta en un sistema de acuerdos de entre los cuales, aquéllos alcanzados con la Santa Sede ${ }^{8}$ tienen naturaleza de tratado internacional, mientras que los concluidos con las Federaciones evangélica, israelita e islámica se plasmaron en las Leyes 24, 25 y 26, de 10 de noviembre de 1992. Tales normas serán tenidas en cuenta con posterioridad en el análisis del papel de la mujer en tales confesiones.

\section{b) Principios y derechos reconocidos}

En todos los conflictos que serán abordados estarán en juego los intereses protegidos por el sistema jurídico religioso internacional, europeo ${ }^{9}$ y español. En el caso de nuestra Constitución ya se ha hecho referencia a que existen una serie de principios fundamentales que inspiran nuestro ordenamiento en cuanto al fenómeno religioso. Ahora nos centramos en analizar el contenido de los mismos, en la medida que nos interesa para el objeto de nuestro estudio. Dichos principios se encuentran recogidos en la dicción del artículo $16 \mathrm{CE}^{10}$.

A la luz del precepto ponemos el acento en las siguientes ideas:

\section{Libertad religiosa}

El derecho a la libertad religiosa se predica tanto para las confesiones como para los individuos que las integran, incluyendo, como no podría ser de otra manera, a todas las mujeres ya practiquen o no cualesquiera de las costumbres y preceptos de tales confesiones.

${ }^{8}$ Los Acuerdos con la Iglesia Católica datan de 28 de julio de 1976 y los cuatro Acuerdos de 3 de enero de 1979, ratificados mediante Instrumentos el 4 de diciembre de 1979 y relativos, respectivamente, a asuntos jurídicos, asuntos económicos, enseñanza y asuntos culturales, y asistencia religiosa a las Fuerzas Armadas y servicio militar de clérigos y religiosos.

${ }^{9}$ En cuanto las normas internacionales y europeas que vinculan a España y regulan la materia se pronuncian, en similares términos: el Pacto Internacional de Derechos Civiles y Políticos (art. 18); Convenio Europeo de Derecho Humanos (art. 9); Carta De Los Derechos Fundamentales de La Unión Europea (art. 10).

${ }_{10}$ Según el cual «1. Se garantiza la libertad ideológica, religiosa y de culto de los individuos y las comunidades sin más limitación, en sus manifestaciones, que la necesaria para el mantenimiento del orden público protegido por la ley. 2. Nadie podrá ser obligado a declarar sobre su ideología, religión o creencias. 3. Ninguna confesión tendrá carácter estatal. Los poderes públicos tendrán en cuenta las creencias religiosas de la sociedad española y mantendrán las consiguientes relaciones de cooperación con la Iglesia Católica y las demás confesiones». 
El contenido del derecho que venimos abordando se sustenta por los derechos a la libertad para creer o no creer, para tener unas $\mathrm{u}$ otras creencias o convicciones, así como la libertad para formar libremente la propia conciencia y el propio pensamiento. También está en íntima relación la libertad para expresar y manifestar esas creencias o convicciones, haciendo partícipes de ellas a otros, transmitiéndolas, enseñándolas y propagándolas, así como también en su aspecto negativo, es decir, el derecho a no ser obligado a declarar sobre las mismas, lo cual está parejo con la libertad para comportarse, o no, de acuerdo con tales convicciones.

También en relación con este derecho nos resulta de un especialísimo interés la cuestión de sus límites. Resalta el profesor CONTRERAS MAZARÍO ${ }^{11}$ que tales límites no son otros que los delimitados por el orden público, habiendo de entenderse éste según la dicción del artículo 3.1 LOLR interpretado en relación con los artículos 1.1 y 10.1 del texto constitucional español. En concreto, el artículo 3.1 LOLR predica que, "El ejercicio de los derechos dimanantes de la libertad religiosa y de culto tiene como único límite la protección del derecho de los demás al ejercicio de sus libertades públicas y derechos fundamentales, así como la salvaguardia de la seguridad, de la salud y de la moralidad pública, elementos constitutivos del orden público protegido por la Ley en el ámbito de una sociedad democrática». Debemos señalar que la doctrina realiza una interpretación restrictiva, en base a la jurisprudencia, advirtiendo en cuanto a esto de los límites de la libertad religiosa la posibilidad de que pueda limitarse cuando atente contra la salud o la "moralidad pública», no ya solo de toda la sociedad en su conjunto sino incluso de un determinado grupo o «clase de sujetos» como puede ser el caso de la situación de las mujeres. De esto pueden obtenerse las siguientes conclusiones fundamentales: 1. Cualquier conducta que atente contra la integridad de determinados sujetos en situación de dependencia, como las mujeres, puede atentar contra la moralidad pública y, por ende, contra el orden público, de modo tal que no podrá quedar en ningún caso amparada en la práctica de costumbres religiosas de ninguna confesión por sobrepasar los límites del derecho a la libertad religiosa; 2. Debe llevarse a cabo una interpretación stricto sensu de los límites a imponer en el ejercicio de la libertad religiosa, lo cual implica que no todo malestar a una determinada simbología o práctica religiosa pueda quedar restringida, como podría darse en el caso de asistir a centros de enseñanza con el velo islámico ${ }^{12}$; pero tampoco

${ }^{11}$ CONTRERAS MAZARÍO, J., Derecho y Factor Religioso (cit.), p. 75.

12 Véase infra. (epígrafe IV). 
podría restringirse tal derecho si el peligro no queda justificado, máxime cuando se limita por medio de una norma de rango inferior al legal ${ }^{13} ; 3$. Y, por último, debe señalarse que cuando se limite indebidamente el derecho a la libertad religiosa habremos de atender a su configuración como derecho fundamental, pues otorga la posibilidad de tutelar el referido derecho subjetivo mediante un procedimiento basado en los principios de preferencia y sumariedad, así como mediante el recurso de amparo (artículos 53.2 y 161.b respectivamente, en conexión con el 16, todos ellos de la CE) ${ }^{14}$.

\section{Igualdad}

La libertad religiosa tampoco puede ser entendida sin el derecho de igualdad. Tal es el punto de esto que los autores (como CONTRERAS MAZARÍO) lo consideran el adjetivo que necesariamente ha de acompañar a los individuos en la protección de su libertad y, en concreto, de la libertad religiosa. Tal principio de igualdad viene a significar la interdicción de toda discriminación. También se debe tener en cuenta este principio en el análisis de nuestro estudio, toda vez que, trasladado al ámbito de determinadas confesiones, impedirá toda discriminación sobre la mujer, tutelando el ejercicio de ésta a un nivel parejo al que se encuentre el varón. Destacamos a este respecto todos los casos relativos a los delitos de odio por razón de género que se produzcan en el ámbito de una confesión (cfr., Infra, epígrafe 5.1). En este sentido, no solo concebimos el principio de igualdad como anejo a la práctica en igualdad de condiciones por individuos de distintas confesiones, sino también dentro de una misma confesión por parte tanto de hombre como de mujeres, en tanto en cuanto todos son titulares del derecho a la libertad religiosa cuyo ejercicio en igualdad ha de protegerse por ser ésta adjetivo de aquélla.

\section{Laicidad y cooperación}

Dos aspectos deben resaltarse en relación con la aconfesionalidad del Estado (vid. Supra): promoción y tutela de la libertad religiosa, así como autonomía de las confesiones religiosas.

En efecto, por un lado, incluye una primera idea en cuanto que implica velar por el reconocimiento, tutela y promoción del derecho

13 Vid. infra. (epígrafe IV.3.A).

14 CONTRERAS MAZARÍO, J., Derecho y Factor Religioso (cit.), p. 69. 
a la libertad de conciencia y religiosa, lo cual, en conexión al principio de igualdad, descubre un marco en el que de manera inseparable ha de presentarse el principio de Estado laico como garantía de tal libertad confesional. En relación a esta dimensión de la laicidad, debemos poner en conexión el principio de cooperación en cuanto que, para CONTRERAS MAZARÍO ${ }^{15}$, tales relaciones de cooperación pueden ser entendidas como una técnica de carácter instrumental por mor de dar efectividad a la libertad de conciencia y religiosa, pero que no puede ligarse a la valoración directa y positiva de los intereses religiosos propiamente entendidos, pues el respeto a la laicidad conlleva que solo pueda relacionarse positivamente el Estado en aras de la protección y promoción de la igualdad en la titularidad y en el ejercicio de la libertad de conciencia.

En segundo lugar, la aconfesionalidad parte de la consideración de independencia y autonomía de las confesiones religiosas, destacando, a tal efecto, el artículo 6 LOLR, el cual garantiza la libertad de gestión de los poderes religiosos tanto en términos organizativos como en lo referente al fenómeno religioso. De acuerdo con esto, debe acentuarse la cuestión que limita el margen de actuación de las autoridades eclesiásticas cuando actúan en favor de decisiones estrictamente religiosas, que no es otro que el respeto y el ejercicio de los derechos fundamentales y, en especial, de la libertad religiosa. Destaca especialmente para nuestro análisis esta segunda dimensión de la aconfesionalidad, en la medida en que sirve para justificar determinadas cuestiones discriminatorias para la mujer ${ }^{16}$ (por ejemplo, acceso a los altos cargos eclesiástico) —vid. infra. (epígrafe 5.2)—.

\section{MUJER Y RELIGIÓN}

Una vez dibujado de forma básica el marco jurídico del actual pluralismo religioso, nos centramos ahora en analizar el papel que juega la mujer en el ámbito religioso, tratando para ello de plasmar una visión general de los factores que pueden influir en ese papel para, posteriormente, poner de manifiesto el rol del género femenino en cada una de las distintas confesiones.

Venimos comprobando desde hace tiempo cuan interesante resulta estudiar la evidente concepción de desigualdad que existe en-

${ }^{15}$ CONTRERAS MAZARÍO, J., Derecho y Factor Religioso (cit.), p. 83.

16 MARTÍNEZ-TORRÓN, J., La igualdad de sexos en el sistema acordado de relaciones entre Estado español y confesiones religiosas. [online] Aequalitas: Revista jurídica de igualdad de oportunidades entre mujeres y hombres, 2012, pp. 63-65. 
tre géneros construida a partir de argumentos sociales, culturales y religiosos. En este trabajo nos interesa, y nos centraremos en plantear, más concretamente, la perspectiva «religión e igualdad de género», es decir, cuál es la situación actual de los derechos de las mujeres en las distintas confesiones religiosas. Es decir, vamos a estudiar la situación de las sociedades en la actualidad en las que, cada vez más a menudo, la discriminación de la mujer en el marco de las religiones se hace palpable a la vez que ciertamente injusto y delictivo.

A este respecto, resulta evidente que se observa una tensión entre los dos extremos que estamos mencionando cuando un reclamo de igualdad sexual choca con una característica que se juzga distintiva de algunas religiones en las cuales hombres y mujeres no deben recibir el mismo trato. Aunque la apuesta del Derecho Internacional sea clara a favor de los derechos de las mujeres en este tipo de conflictos, se debe desechar la opción de darles siempre una única respuesta porque ello significaría desconocer el valor normativo del respeto a la diversidad religiosa, a salvo claro está de los casos de violencia contra la mujer, en los cuales siempre se debe estar a favor de su eliminación. Así, al abordar los conflictos entre los derechos de las mujeres y la diversidad religiosa, estos deben ser situados geográfica e históricamente y no se puede dejar de considerar la posición de las mujeres pertenecientes a una concreta religión, partiendo de la base de que las religiones han cambiado poco a lo largo de la historia y son conflictivas al tiempo que usadas, en muchas ocasiones, para mantener espacios de poder.

Las sociedades occidentales del siglo XXI, multiculturales, multiétnicas y pluri-religiosas, están llamadas a diseñar un nuevo sistema de convivencia pacífica que garantice la libertad y los derechos de todos, a partir del pacto jurídico recogido en los textos constitucionales $^{17}$. En este sentido, en un contexto social caracterizado por la irrupción pública de un sugerente mosaico cultural y religioso se están suscitando continuamente nuevos desafíos jurídicos a los que habrá que dar respuesta utilizando las herramientas que ofrezca cada ordenamiento jurídico y una de ellas será el mayor y más escrupuloso respeto de los derechos humanos y las libertades funda-

17 Cfr., SUÁREZ PERTIERRA, G.: «Individuo, grupos, confesiones en el sistema democrático español», Religión, religiones, identidad, identidades, minorías: actas del V Simposio de la Sociedad Española de Ciencias de las Religiones, Coord. Fernando Amérigo, Valencia 1-3 de febrero de 2003, SECR, pp. 7-24. 
mentales, al erigirse como una de las mayores conquistas jurídicosociales de la humanidad $^{18}$.

No se puede perder de vista que los conflictos entre las religiones y los derechos de las mujeres no son recientes. Es más, la lucha por el reconocimiento de los derechos de las mujeres es, en sí misma, una lucha en contra de la cultura patriarcal que domina todas las sociedades y la mayor parte de las religiones del mundo y es por ello que las contradicciones entre lo que se observa en las prácticas religiosas y los reclamos por los derechos de las mujeres han sido, son y seguirán siendo una constante. Aunque no se traten estos conflictos de un tema reciente, la realidad nos muestra que últimamente ha cobrado una inusitada actualidad, sobre todo en los medios de comunicación internacionales, debido a la importancia que están adquiriendo en la actualidad las doctrinas jurídicas feministas. Sin considerarnos feministas, sí nos consideramos fieles defensores de articular políticas que hagan posible el reconocimiento de la dignidad de las mujeres en las religiones.

El objetivo de este estudio ha sido tratar de profundizar, en libertad, en aquellos aspectos relacionados con la igualdad de género en el ámbito de las religiones y de su influencia en la sociedad, proponiendo desde una Europa y, sobre todo, una España laica como la nuestra, no dar ni un paso atrás en los derechos conquistados y exigir los que faltan por conquistar.

No puede olvidarse que al hablar de los derechos de las mujeres se hace referencia, fundamentalmente, al derecho a la igualdad y ello porque gran parte de los conflictos con la diversidad religiosa se genera debido a que se reconocen derechos, se adscriben deberes o se desarrollan ciertas prácticas de forma diferenciada según el sexo, distribución en la cual las mujeres siempre tienen menos derechos, más deberes y son el sujeto, o más bien el objeto, de prácticas perjudiciales para sus derechos.

Junto a esto, debemos señalar que, además de esta diferenciación señalada entre el hombre y la mujer en las confesiones religiosas, también hay que considerar la diferente posición de las propias mujeres pertenecientes o practicantes de una misma religión: no se

18 Vid., GARCÍA RUIZ, Y.: «Pluralidad religiosa, diversidad cultural y derechos de la mujer: Novedades jurisprudenciales en España», Gestión de la diversidad cultural en las sociedades contemporáneas, Directores M. ${ }^{a}$ TERESA REGUEIRO GARCÍA y SALVADOR PÉREZ ÁLVAREZ, Tirant lo Blanch, Valencia, 2014, pp. 325-348. 
puede asumir que un determinado concepto de igualdad o de derechos es compartido por todas las mujeres del mundo ${ }^{19}$.

Las actuales discusiones en torno a los derechos de las mujeres y el respeto a la diversidad religiosa no son radicalmente distintas de las discusiones que se han dado a lo largo de la historia cuando las mujeres han reclamado el reconocimiento de sus derechos. En todas las naciones, etnias y religiones se han dado, se dan y se darán discusiones de este tipo: algunas han producido ya cambios importantes y otros están pendientes de producirlos; es un hecho, como comprobaremos en este trabajo, que las actuales discusiones en torno a este tema no son más que una continuación del reclamo por la igualdad sexual y por la protección de los derechos y libertades más fundamentales y así deben ser entendidas y resueltas ${ }^{20}$. La sumisión de la mujer, su relegación al ámbito privado o familiar y el control sobre su sexualidad, está detrás de muchas de las tradiciones que han llegado a nuestro país de la mano de comunidades procedentes de países donde dichas tradiciones están fuertemente arraigadas. El choque entre los derechos reconocidos a las mujeres en nuestro ordenamiento jurídico y la negación de los mismos, implícita en di-

19 En este sentido hemos podido comprobar cómo se ha afirmado, muy acertadamente en nuestra opinión, que "Incluso dentro de una misma nación, etnia o religión existen divergencias entre las posiciones de las mujeres porque la cultura y la religión no afectan de igual manera la vida de todas las mujeres: también existen componentes sociales, económicos y geográficos que inciden en su estatus»: ARDILA TRUJILLO, M.: «Hacia la resolución de los conflictos entre la protección de la diversidad cultural y el reconocimiento de los derechos de las mujeres», Revista Derecho del Estado, $n .^{\circ}$ 26, enero-junio, 2011, pp. 137-152.

${ }^{20}$ Cfr., GARCÍA RUIZ, Y.: "Pluralidad religiosa, diversidad cultural y derechos de la mujer: Novedades jurisprudenciales en España», op. cit., pp. 325-348: «En España, el incremento de los flujos migratorios de las últimas décadas ha favorecido la creciente diversidad cultural y religiosa y ha propiciado un innegable enriquecimiento cultural. Junto a dicha riqueza, la inmigración ha importado también prácticas consuetudinarias, sustentadas en modelos patriarcales, que están generando nuevos desafíos y pueden amenazar la frágil conquista de las libertades y los derechos de la mujer en nuestro país. Algunos de dichos derechos y libertades son demasiado recientes y la consolidación de otros se encuentran en proceso todavía en muchos ámbitos. Por ello, no conviene despreciar los riesgos que subyacen tras algunas tradiciones que cuestionan la dignidad de la mujer y que atentan contra sus derechos más fundamentales». También: CASTRO JOVER, A.: «Inmigración, pluralismo religioso y educación», Laicidad y libertades: escritos jurídicos, $n .{ }^{\circ} 2$, 2002, pp. 89 a 119; FERNÁNDEZ-CORONADO GONZÁLEZ, A.: «Matrimonio islámico, orden público y función promocional de los derechos fundamentales», Revista Española de Derecho Constitucional, 29, n. ${ }^{\circ} 85$, 2009, pp. 125-156; JORDÁN VILLACAMPA, M.L.: "Religión y derecho en la España de la primera década del tercer milenio», Ilu. Revista de Ciencias de las religiones, Anejos, XI, 2004, pp. 41 a 50; COMBALÍA SOLÍS, Z.: "¿Igualdad o equidad?: el reconocimiento en occidente de instituciones islámicas de inspiración patriarcal», Igualdad efectiva entre mujeres y hombres: diagnóstico y prospectiva, Atelier, 2009, pp. 21-48. 
chas tradiciones, ha dado lugar a un encendido debate social y a pronunciamientos jurisprudenciales recientes en nuestro país que conviene analizar.

\section{III.1. Retomando el multiculturalismo a propósito de su influencia en la mujer}

Cuando planteábamos al inicio aquellos factores que han de tenerse presentes para contextualizar la cuestión que nos ocupa hablábamos de la importancia que tiene el multiculturalismo y el pluralismo religioso. Retomamos ahora tal cuestión para centrarnos en la influencia que ese elemento del contexto tiene sobre la figura femenina. A este respecto, se cuestiona SALAZAR BENÍTEZ si el multiculturalismo acaba perjudicando a la mujer, llegando a la conclusión de que no se acaban de tener en cuenta los límites que el pluralismo cultural ha de presentar para respetar la garantía de los derechos y principios constitucionales ${ }^{21}$. Además, considera el autor que la mayoría de conflictos que se manifiestan en el seno de un contexto multicultural "tienen un marcado carácter de género», por desarrollarse en ámbitos marcadamente patriarcales. Asimismo, considera que actualmente es más importante si cabe la cuestión del pluralismo cultural y religioso, y su afectación a la esfera femenina, en cuanto que surgen con fuerza, por un lado, discursos fundamentalistas de las religiones y, por otro, reacciones «neomachistas» ante la progresiva conquista de derechos por parte de las mujeres. Frente a ello, GARCÍA VÁZQUEZ ${ }^{22}$ pone el acento en el cada vez más acusado proceso de secularización que sufren las religiones en Europa del que ni siquiera el islam se escapa.

De uno u otro modo, es decir, ya afecte en mayor medida el proceso secularizador o el discurso fundamentalista en el ámbito de las confesiones, sí que parece decisivo el fuerte impacto de la inmigración a nivel social y su afectación directa en los Estados laicos y democráticos, en los que se habrá de garantizar, cada más en mayor medida, el respeto, la tolerancia y la libertad de las confesiones que profesen los sujetos inmigrantes. Sin embargo, esta tolerancia no

${ }^{21}$ SALAZAR BENÍTEZ, O., La autonomía relacional de las mujeres (...) cit. Primer Epígrafe: Introducción: ¿es el multiculturalismo malo para la mujeres?

${ }^{22}$ GARCÍA VÁZQUEZ, S., El derecho a la libertad religiosa y el uso del velo islámico... cit., p. 374. En efecto, señala una cada vez más fuerte distinción de las familias musulmanas atendiendo, como criterio diferenciador, a la adhesión al islam, aspecto del que deriva la reproducción en mayor o menor medida de los roles en el seno de la familia, de ahí su peso que juegue sobre la mujer. 
puede ser absoluta, habiendo de limitarse en la medida en que las costumbres de las distintas confesiones atenten contra los valores y principios más elementales de nuestro ordenamiento, con especial atención a la dignidad humana (artículo $10 \mathrm{CE}$ ) y, en este sentido, la dignidad de la mujer.

A estos efectos, es interesante destacar al profesor LÓPEZ-SIDRO LÓPEZ ${ }^{23}$, quien considera que la preocupación por el uso del burka en nuestras sociedades occidentales es relativamente reciente. En concreto sitúa el punto de inflexión de esta preocupación en el comienzo de la guerra en Afganistán, por convertirse desde este momento la mujer afgana en icono de la mujer sometida a un trato degradante e inhumano, y su vestimenta en una figura con un claro matiz opresor.

En todo caso, reputo como de mayor interés para nuestro estudio la plasmación de ese pluralismo en nuestro ordenamiento jurídico. Define SALAZAR BENÍTEZ a los sistemas de pluralismo jurídico como «aquellos en los que se reconoce la vigencia de normas singulares de comunidades así como de los procedimientos particulares de resolución de conflictos ${ }^{24}$. Aboga el autor porque estos sistemas no renuncien a la vigencia indiscutible de los derechos fundamentales, en especial de las mujeres, en la media en que los Estados puedan acudir a las especificidades culturales para legitimarla violación de los derechos de las mujeres. De hecho, continúa destacando el autor que la mayor parte de las reservas formuladas por los Estados a la Convención sobre la eliminación de todas las formas de discriminación contra la mujer se fundamentan en la especificidad cultural. Con todo, y habida cuenta de la relevancia que el pluralismo cultural y religioso puede tener, y de hecho tiene en nuestra sociedad en general, y en la figura de la mujer en particular, comenzamos a analizar el papel de la mujer en las confesiones con las que coopera nuestro Estado.

${ }^{23}$ LÓPEZ-SIDRO LÓPEZ, Á. «Restricciones al velo integral en Europa y en España: la pugna legislativa para prohibir un símbolo», Revista General de Derecho Canónico y Derecho Eclesiástico del Estado, 32, 2013, p. 2.

24 SALAZAR BENÍTEZ, O., La autonomía relacional de las mujeres (...) cit., pp. 230 y ss. 


\section{III.2. Perspectivas generales de la mujer en la religión}

a) Justificación de la violencia y discriminación por motivos religiosos

En palabras de SOUTO GALVÁN, «la gestión de la diversidad cultural es uno de los grandes desafíos que deben afrontar los países democráticos, en especial, en relación con la situación de las mujeres, constante foco de polémicas, [...] el debate entre integración y multiculturalismo, el respeto a la diversidad cultural y los derechos de las mujeres plantean conflictos de indudable interés. Entre otros, precisamente se encuentra la determinación de los limites que puede imponer el legislador a la difusión de estereotipos sexistas o incluso la provocación a la violencia contra las mujeres por parte de grupos religiosos y/o culturales» ${ }^{25}$.

Partiendo de esta idea desarrollaremos el presente epígrafe. La autora pone el acento en el límite a la diversidad cultural, y con ello al pluralismo religioso, en el respeto a los derechos de las mujeres, si bien no de manera absoluta en cuanto que entrará en juego el papel que jueguen las mujeres en los ideales de las confesiones, prácticas amparadas en la libertad religiosa, pero que cuyo límite, como vimos supra (epígrafe 2.2 a), y así lo resalta la autora, no puede excederse hasta incitar a la provocación a la violencia contra las mujeres, independientemente que dentro del rol que juegue la mujer en la confesión sea admisible, lo cual también es discutible.

A este respecto, debemos precisar que el concepto de violencia de género va más allá que la agresión física del hombre hacia la mujer, puesto que incluye formas muy variadas de sometimiento ${ }^{26}$. La importancia de eliminar cualquier tipo de violencia sobre la mujer llegó a la ONU en 1979 con la Convención sobre la eliminación de todas las formas de discriminación contra la mujer, en la que se insistió a los Estados partes en la importancia de «modificar los patrones socioculturales de conducta de hombres y mujeres, con miras a alcanzar la eliminación de los prejuicios y las prácticas consuetudinarias y de cualquier otra índole que estén basados en la idea de inferioridad o

${ }^{25}$ SOUTO GALVÁN, B., "Discurso del odio: Género y libertad religiosa», Revista General de Derecho Penal, 23, 2015, p. 3.

${ }^{26}$ El art. 1.3 de la Ley Orgánica 1/2004, de 28 de diciembre, de Medidas de Protección Integral contra la Violencia de Género, define este concepto como «La violencia de género a que se refiere la presente Ley comprende todo acto de violencia física y psicológica, incluidas las agresiones a la libertad sexual, las amenazas, las coacciones o la privación arbitraria de libertad». 
superioridad de cualquiera de los sexos o en funciones estereotipadas de hombres y mujeres» (artículo 5) ${ }^{27}$. Posteriormente, se volvió a pronunciar la ONU en su Asamblea general sobre la debatida cuestión y promulgó la Declaración sobre la eliminación de la violencia contra la mujer cuyo artículo 4 señala que «los Estados deben condenar la violencia contra la mujer y no invocar ninguna costumbre, tradición o consideración religiosa para eludir su obligación. Los Estados deben aplicar por todos los medios apropiados y sin demora una política encaminada a eliminar la violencia contra la mujer» (art. 1.3 de la Resolución de la Asamblea General 48/104 del 20 de diciembre de 1993). En ambas disposiciones se acentúa la necesidad de modificar «patrones socioculturales», y "prácticas consuetudinarias», en cuanto que «no puede invocarse ninguna costumbre, tradición o consideración religiosa» que sustenten cualquier tipo de sometimiento de género.

Como evidenciamos con las noticias que nos llegan constantemente de los medios de comunicación, este tipo de prácticas y patrones de discriminación supone un mal que afecta a todos los estratos de la sociedad y no solo al entorno de determinadas confesiones religiosas. No obstante, el objeto que a nosotros nos ocupa en este trabajo y que nos viene interesando hace ya unos años nos lleva a analizar el papel que esa discriminación tiene en el ámbito religioso. Al respecto es interesante la cita que SOUTO GALVÁN ${ }^{28}$ hace de JUAN JOSÉ TAMAYO, Director de la Cátedra de Teología y Ciencias de las Religiones de la Universidad Carlos III de Madrid, quien en un artículo titulado «Discriminación de las mujeres y violencia de género en las religiones» afirma que «las religiones son uno de los lugares donde las mujeres sufren una de las más radicales experiencias de silenciamiento, discriminación e invisibilización». Con estas palabras del autor se pone de manifiesto la importancia que adquiere este tipo de violencia y discriminación en el ámbito religioso, lo cual será objeto de análisis en un momento posterior (infra epígrafe 5.1: vid. Caso del Imán de Fuengirola y Caso del imán de Terrasa).

b) Rol de la mujer a causa de la religión

Siendo el objetivo del presente epígrafe aproximar la posición de la mujer en el interior de las distintas confesiones, conviene analizar la cuestión, al menos sucintamente, desde el punto de vista de la p. 25 .

27 SOUTO GALVÁN, B., «Discurso del odio: Género y libertad religiosa», op. cit.,

${ }^{28}$ SOUTO GALVÁN, B., «Discurso del odio: Género y libertad religiosa», op. cit., p. 25 . 
antropología. Así, la profesora CASTILLA VÁZQUEZ considera que el sistema sexo/género es «el conjunto de normas que cada sociedad utiliza para transformar la sexualidad biológica en producto cultural. Cada cultura tiene su propio sistema mediante el cual normativiza el sexo" y define las diferencias sexuales y lo que es sexualmente correcto o incorrecto. La asignación del género se efectúa a muy temprana edad y esta asignación lleva aparejada una serie de roles que hemos de desempeñar, ordenados por la cultura en la que hemos nacido $^{29}$. Desde esta perspectiva, y a la vista de la importancia que la religión tiene sobre las costumbres practicadas en el seno de las confesiones y, de manera más general, sobre la cultura de cualquier sociedad, podemos concebir que el rol que la mujer desempeñe quedará fuertemente vinculado a la confesión que practique.

Sentada la envergadura de la cultura y la religión en la posición que ocupará la mujer en la sociedad en la que se desarrolle, nos ocupamos ahora de analizar si tal posición se presenta en pie de igualdad o de supeditación al hombre. La cuestión fue tratada por el profesor MARTÍNEZ TORRÓN quien considera que «si utilizamos las categorías conceptuales propias de la cultura jurídica occidental contemporánea, la mujer ocupa una posición inferior a la del varón, tanto en la Iglesia católica como en las otras confesiones incluidas en el régimen de acuerdos de cooperación de 1992». Y continúa el autor que "en realidad, no es fácil encontrar comunidades religiosas en el mundo donde pueda observarse una completa equiparación entre mujer y varón» ${ }^{30}$. Esta subordinación es también destacada por CASTILLA VÁZQUEZ. Pero va más allá la autora al estimar la necesidad de abordar tal desigualdad bajo el paraguas de la religión, toda vez que manifiesta la autora, "en muchas ocasiones encontramos en las creencias religiosas y sobre todo en los tabúes, el origen de esas discrepancias tradicionales, que al sacralizarse se perpetúan en la sociedad, fomentando la ya extendida desigualdad de trato entre hombres y mujeres».

La cuestión es que, en definitiva, además de la posición de desigualdad por razón de sexo en nuestro ordenamiento jurídico, los tradicionales sistemas de dominación patriarcal, se han convertido en normas de conducta que, desarrolladas en el seno de las confesiones, han cobrado especial arraigo hasta el punto de que, todavía hoy, son utilizadas como herramientas para mantener a las mujeres en situación de dependencia.

${ }^{29}$ CASTILLA VÁZQUEZ: «Eso no se hace, eso no se toca, de eso no se habla. La desigualdad de género en las religiones», Gazeta de Antropología, 2009, 25 (2), artículo 40 .

${ }^{30}$ MARTÍNEZ-TORRÓN, J., La igualdad de sexos (cit.), p. 63. 


\section{III.3. Perspectivas particulares de la mujer en cada confesión}

Trasladamos ahora lo anterior al ámbito interno de cada confesión.

a) Catolicismo

En opinión de SALAZAR BENÍTEZ, todavía hoy, en nuestros días, las estructuras de la Iglesia Católica siguen discriminando a las mujeres en contra de lo que establece el ordenamiento jurídico de los Estados europeos ${ }^{31}$.

La cuestión incide en el ámbito privado de la mujer, así, CASTILLA VÁZQUEZ señala que ha sido siempre tabú cualquier tema relacionado con la sexualidad especialmente de la mujer. En todo caso, como continúa la autora, el papel de la mujer en el ámbito familiar queda en una posición subordinado a la atención de la familia, mientras que el hombre es el protector del núcleo familiar ${ }^{32}$. No obstante, no fue hasta el Concilio Vaticano II cuando se tomó importantica de la mujer en el seno de la Iglesia Católica. Así, destaca que el Concilio Vaticano II se dio en un momento en que, a pesar de que la figura de la mujer estaba oscurecida por la del hombre, comenzaba a ganar los derechos que venía reclamando durante varias décadas. Este aspecto influyó no solo en la dignidad de la mujer en la Iglesia, sino en su involucración en tal seno ${ }^{33}$. Hasta tal fue el punto que podemos encontrar el siguiente mensaje en el Concilio: "ha llegado la hora en que la vocación de la mujer llega a su plenitud [...] un poder que jamás ha adquirido hasta ahora [... $]^{34} »$.

Especial referencia a la falta acceso a los cargos eclesiásticos y su justificación

Especial referencia merece la discriminación que sufre hoy día la mujer en lo relativo al acceso a posiciones de responsabilidad en la administración y gobierno de la Iglesia, ello bajo la influencia de

31 SALAZAR BENÍTEZ, O., La autonomía relacional de las mujeres (...) cit., en que menciona a SUNSTEIN (p. 231).

${ }^{32}$ CASTILLA VÁZQUEZ: "Eso no se hace, eso no se toca, de eso no se habla. La desigualdad de género en las religiones», op. cit..

${ }_{33}$ La figura de la mujer en la vida de la Iglesia. Agencia Fides, 12/08/2008, p. 1.

${ }^{34}$ Ibid. p. 3. 
un liderazgo patriarcal ${ }^{35}$. En relación a lo anterior, la cuestión ha sido debatida en el seno de la Iglesia, lo que conllevó que en 1994 el, por aquel entonces Papá, Juan Pablo II, se pronunciara en contra del acceso de las mujeres como sacerdotes ${ }^{36}$. Igualmente se pronunció Benedicto XVI en 2007, quien llegó a promulgar Decreto General con el que amenazaba con la excomunión a las mujeres que propugnen por acceder a las órdenes sagradas ${ }^{37}$. Si bien, parece que actualmente el Papa Francisco aboga por el debate y por un papel de mayor peso de la mujer en el ámbito de la familia católica y, además, en el propio seno de la Iglesia ${ }^{38}$.

$\mathrm{Al}$ parecer, la idea de fondo de esta discriminación trae su fundamento en que Cristo escogió sus Apóstoles solo entre varones, por lo que ha sido práctica constante de la Iglesia escoger sólo varones, por lo que entre sus autoridades más altas se excluye a la mujer ${ }^{39}$.

Conviene dejar a un lado los fundamentos teocráticos y propios de la confesión que desembocan esta imposibilidad de la mujer de acceder a los cargos de poder en la Iglesia, para centrarnos en las cuestiones jurídicas que permiten que ello sea posible en nuestro país. Al respecto, bien señala MARTÍNEZ TORRÓN ${ }^{40}$ considerando que, en base a la autonomía institucional de que goza la Iglesia, el Estado no puede inmiscuirse y exigir cambiar las coordenadas de acceso de la mujer a los altos cargos eclesiásticos en condiciones de igualdad. Por ello, las confesiones no están obligadas a organizarse de modo democrático, pues no tienen por qué seguir los dictados de los sistemas actuales de Derechos Humanos, considerando MARTÍNEZ TORRÓN que su imposición iría en contra de la religión y que, por ende, solo podría intentar el Estado revertir la situación, en palabras citadas del TEDH, por una «necesidad

35 MARTÍNEZ-TORRÓN, J., La igualdad de sexos (cit.), pp. 63-34.

36 MARIA MORAN, G., "La igualdad religiosa y la mujer en las iglesias cristianas: su incorporación jurídica a las órdenes sagradas», Stato, Chiese e pluralismo confessionale. Rivista telematica (www.statoechiese.it), 2015, p. 4. Juan Pablo II se pronunció según la siguiente dicción: «por tanto, con el fin de alejar toda duda sobre una cuestión de gran importancia, que atañe a la misma constitución divina de la Iglesia, en virtud de mi ministerio de confirmar en la fe a los hermanos, declaro que la Iglesia no tiene en modo alguno la facultad de conferir la ordenación sacerdotal a las mujeres, y que este dictamen debe ser considerado como definitivo por todos los fieles de la Iglesia».

37 MARIA MORAN, G., "La igualdad religiosa y la mujer en las iglesias cristianas: su incorporación jurídica a las órdenes sagradas», op. cit., p. 7.

38 http://www.news.val es/news/la-iglesia-es-mujer-es-la-iglesia-no-el-iglesia-pa, Aquí puede consultarse un discurso del Papa Francisco el 7/3/2015.

39 Ibíd. p 3 y 4.

40 MARTÍNEZ-TORRÓN, J., La igualdad de sexos (cit.), pp. 64. 
social imperiosa». No debemos olvidar que la autonomía eclesiástica queda amparada constitucionalmente por ser parte integrante de la aconfesionalidad del Estado, como tuvimos ocasión de ver supra (epígrafe 2.2 b). Estas conclusiones son, pues, extrapolables al resto de confesiones.

\section{Especial referencia a la presencia femenina en las cofradías}

En relación con esta cuestión también puede resultar interesante añadir una pincelada, brevemente por supuesto por razones de espacio, sobre el papel de la mujer en las hermandades y cofradías, que tanta importancia parece tener en ciudades en las cuales, como Sevilla, ese micro-macro mundo tiene tantísima relevancia de todo tipo.

Un asunto que es de un gran interés en la ciudad mencionada es el hecho de que históricamente han existido dificultades para la presencia de mujeres en las cofradías sevillanas. Sin embargo, en cuanto a salir de nazareno, es relevante el Decreto, en 2011, del Arzobispo de Sevilla, Monseñor Juan José Asenjo Pelegrina, con el que se pretendía impedir la discriminación en las procesiones sevillanas ${ }^{41}$. Del mismo modo, el acceso a las Juntas de Gobierno de determinadas hermandades por parte de las mujeres se ha venido antojando también complicado, en la medida en que los Estatutos de varias hermandades lo han venido impidiendo durante años ${ }^{42}$.

\section{b) Evangelismo}

La situación de la mujer en la religión evangélica no dista demasiado de la comentada en cuanto a la religión católica. En lo relativo al ámbito familiar, y en base a la regulación del matrimonio, la consideración en cuanto al equilibrio de género es simétrica ${ }^{43}$. Por su parte, las iglesias de origen protestante han sido más flexibles que las católicas en la incorporación de la mujer, como también lo fueron en la abolición de la esclavitud. Tal es el punto que, aunque no de manera absoluta, ha existido la posibilidad de que las muje-

41 http://www.abc.es/20110203/sociedad/abcp-mujeres-nazarenasdecreto-20110203.html - Rescatada el 25/2/2017.

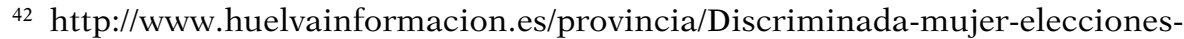
cofradia_0_534247280.html / http://www.lavozdigital.es/cadiz/201411/22/mujerespioneras-semanasanta-20141121193257-pr.html - Rescatadas el 25/2/2017.

${ }^{43}$ MARTÍNEZ-TORRÓN, J., La igualdad de sexos (cit.), p. 66. 
res accedan a los altos cargos de autoridad eclesiástica en esta religión ${ }^{44}$.

c) Confesión islámica

El papel de la mujer en la religión islámica es controvertido. Cada vez brotan con mayor fuerza las ideas de aquellos partidarios por una interpretación del Corán adecuada a los tiempos y a la realidad social actual, al menos en los países occidentales.

Trataremos de sintetizar esta visión teórica del género femenino en el islam atendiendo a los estudios de NASSIRA SEDIRI ${ }^{45}$, autora que trata de justificar una correcta interpretación del Corán, así como la Sunah (lo que fue narrado por Mahoma) y la Iytihad (razonamiento individual), fuentes de la ley islámica. Para la autora, la idea de fondo del Corán trae causa en el respeto entre todos los musulmanes, ya sean hombres o mujeres, si bien la realidad histórica ha propiciado que se imponga una visión patriarcal unitaria cuyas consecuencias han sido soportadas por la mujer, especialmente en los países de fuerte influencia árabe. Hasta tal es el caso que rescata la autora un estudio del PNUD (Programa de Naciones Unidas para el Desarrollo) en el que se analizan los diez peores países para ser mujer, llegando al resultado de incluir entre los mismos hasta a siete países musulmanes. Esta situación queda referenciada en los derechos civiles (por ejemplo las mujeres heredan por mitad), políticos, en cuanto a la dignidad (uso del velo islámico) e incluso en cuanto al matrimonio. En este sentido, tenemos, por ejemplo, la división sexual del espacio público y privado para la práctica de determinados rituales religiosos: en la mayoría de las mezquitas en España la casi totalidad de los asistentes son hombres, estando en muchos casos prohibida la entrada a las mujeres, por ello, para las mujeres el espacio habitual para la práctica de la oración es la casa.

Nos detenemos en la discriminación en cuanto al matrimonio pues, si bien es cierto que hoy en día la poligamia está en clara decadencia, podríamos decir inexistente en las sociedades europeas, la cuestión es interesante desde un punto de vista jurídico en nuestro país. En los acuerdos de nuestro Estado con las confesiones minoritarias (Leyes 24, 25 y 26/ 1992) el artículo 7 de cada uno hace re-

${ }^{44}$ MARÍA MORÁN, G., "La igualdad religiosa y la mujer en las iglesias cristianas: su incorporación jurídica a las órdenes sagradas», op. cit., p. 1-2.

${ }^{45}$ NASSIRI SEDIRI, 2014. La realidad de la mujer en el islam. Tesis de máster, María Socorro Suárez Lafuente (dic).

(c) UNED. Revista de Derecho UNED, núm. 23, 2018 
ferencia a los efectos civiles que tiene el matrimonio celebrado según los ritos de esas confesiones. No obstante, el precepto de la Ley 26/1992, Acuerdo con la Comunidad Islámica, recoge que el certificado de capacidad matrimonial, necesario para dotar de efectos civiles al matrimonio celebrado ante una autoridad religiosa de la confesión que sea, puede ser expedido después de celebrado el matrimonio, solo bastando que sea antes de la inscripción en el Registro civil (lo que dotaría de los referidos efectos civiles) ${ }^{46}$. Este aspecto es considerado por MARTÍNEZ TORRÓN ${ }^{47}$ como la posibilidad de poligamia encubierta pues, si bien solo tendrá efectos civiles el matrimonio inscrito (solo puede inscribirse uno), el varón musulmán podrá celebrar tantos matrimonios como le permitan los dictados islámicos ${ }^{48}$.

Para conseguir llegar al objetivo que este epígrafe pretende, esto es, contextualizar la situación de la mujer en el islam, debemos quedarnos con la idea de que el género femenino se enfrenta a distintas tradiciones o costumbres que, ya provengan o no de una correcta interpretación de la ley islámica, posicionan a la mujer en un segundo plano con respecto al hombre, con instituciones que atentan contra los derecho más básicos de la mujer y que, por tal motivo, son objeto de protección por los más elementales textos normativos, como el Convenio Europeo de Derechos Humanos y las constituciones de los Estados europeos.

\section{d) Judaísmo}

En el judaísmo el papel de la mujer no queda tan restringido como puede quedar en el islam, si bien deben tenerse presentes distintas corrientes con diverso grado de patriarcalismo. Así, el judaísmo ortodoxo es el más radical en el sometimiento a la mujer, si bien en Europa gozan de plenitud entre los judíos las corrientes reformistas, así es el caso de los sefardíes en España ${ }^{49}$.

No obstante, MARTÍNEZ TORRÓN ${ }^{50}$ considera que el matrimonio en el mundo judío es «asimétrico» en cuanto que no existe una

\footnotetext{
46 Sin embargo, en las confesiones evangélica y judía el certificado ha de expedirse antes de la celebración.

47 MARTÍNEZ-TORRÓN, J., La igualdad de sexos (cit.), p. 66.

${ }^{48} \mathrm{Al}$ respecto, destaca NASSIRI SEDIRI una cita del Corán que dice: «[...] casaos con las mujeres que os gusten; dos, tres o cuatro [...]».

${ }^{49}$ SALVATIERRA OSSORIO, A. Esposas y madres, la mujer en el judaísmo clásico, año 54, n. ${ }^{\circ} 913,2004$, pp. 26-31.

50 MARTÍNEZ-TORRÓN, J., La igualdad de sexos (cit.), pp. 66.
} 
equiparación jurídica entre la figura del varón y la mujer. Por este motivo, la eficacia de los matrimonios en este ámbito se limita en nuestro ordenamiento a la mera celebración, rigiendo para el resto de efectos los previstos en nuestro Código civil ${ }^{51}$.

En el seno de las prácticas religiosas podemos destacar, en lo que a las sinagogas se refiere, que los hombres suelen situarse delante y las mujeres detrás e incluso en ocasiones podemos encontrar a modo de separación simbólica, una pequeña celosía, o simplemente una fila de bancos. En el mismo sentido, tampoco está plenamente reconocido el acceso de la mujer al rabinato.

\section{VELO ISLÁMICO}

\section{IV.1. Velo: origen, concepto y tipos}

Hasta aquí hemos tratado de contextualizar el papel que desarrolla la mujer en el ámbito religioso estudiando la cuestión desde el punto de vista de los conflictos que puedan surgir en dicho ámbito. Ahora centraremos nuestra atención en la cuestión que más debate ha venido suscitando desde hace unos años en el ámbito que estamos analizando, a saber, la utilización del conocido velo islámico. Vamos así a describir en este apartado lo poco o lo mucho que nos permitan nuestras limitaciones de espacio sobre el estado actual de la cuestión del porte del velo islámico, doctrinal y jurisprudencialmente, como importantísimo desafío jurídico que es en nuestra España del presente siglo XXI.

\section{a) Origen}

Una primera matización de relativo interés es el hecho de situar el origen de la tradición de llevar el velo no en las mujeres musulmanas, sino por los antiguos asirios que pretendían etiquetar a las mujeres de alta posición social. En la misma línea, en la Arabia preislámica, servía para distinguir a las mujeres libres de las esclavas.

De hecho, durante los primeros años del Islam las mujeres prescindían del uso del velo, lo cual fue cambiando en la medida en que

${ }^{51}$ En concreto, el autor pone de relieve el reconocimiento inferior de este matrimonio, al igual que el islámico, con respecto al reconocimiento del matrimonio canónico. 
los hombres decidieron adoptar una postura de liderazgo religioso patriarcal de la mano de interpretaciones extremas del Corán ${ }^{52}$.

\section{b) Conceptuación y tipos}

Sea cual fuere su origen, el velo islámico se trata hoy día de una prenda característica de la vestimenta de la mujer practicante del Islam, en cumplimiento del código hiyab ${ }^{53}$. No obstante, conviene precisar los distintos tipos de velo con los que nos podemos encontrar, pues la consideración de uno u otro en los conflictos que puedan surgir no es baladí, como veremos.

A estos efectos, el más típico en occidente es aquel velo que deja completamente visible la parte de la cara, conocido como hi$y a b$. Por otro lado, tenemos la shayla que es un pañuelo de forma rectangular que se coloca sobre la cabeza, dejando el rostro a la vista, muy característico del golfo pérsico. Siguiendo con la clasificación encontramos el burka, el cual oculta completamente el cuerpo de la mujer, incluso el rostro, contando con una pequeña rejilla para que la mujer pueda «ver». Aunque pueden existir más tipos destacamos por último el niqab, concepto con el que se denomina a una larga túnica que cubre completamente el cuerpo y la cabeza, dejando al descubierto exclusivamente los ojos de la mujer ${ }^{54}$.

A pesar de la enorme tipología de vestimenta de la mujer islámica con la que nos podemos encontrar, la única consideración que

${ }^{52}$ GARCÍA VÁZQUEZ, S., El derecho a la libertad religiosa y el uso del velo islámico... cit., p. 377.

${ }_{53}$ Precisa el profesor LÓPEZ-SIDRO LÓPEZ, Á. en «Restricciones al velo integral en Europa y en España: la pugna legislativa para prohibir un símbolo», op. cit., que el concepto hace referencia a «diversas normas de conducta que debe seguir la mujer musulmana para evitar que una inadecuada exposición de su cuerpo genere miradas inapropiadas hacia ella», basándose en los estudios de CATALÁ, S., "Libertad religiosa de la mujer musulmana en el Islam y uso del velo», en MOTILLA DE LA CALLE, A. (coord.), El pañuelo islámico en Europa, Marcial Pons, Madrid, 2009, pp. 45-46.

${ }^{54}$ Para la clasificación hemos atendido a GARCÍA VÁZQUEZ, S., El derecho a la libertad religiosa y el uso del velo islámico... cit., p.377, si bien puede resultar interesante el siguiente sitio web en el que se muestran imágenes de cada uno de los tipos definidos: http://www.infobae.com/2015/08/08/1746595-cuales-son-y-queconsisten-los-distintos-velos-del-mundo-musulman/ Recuperado el 20 de febrero de 2017. Asimismo, para una descripción más pormenorizada de los tipos de velos, véase CATALÁ, S., "Libertad religiosa de la mujer musulmana en el Islam y uso del velo», en MOTILLA DE LA CALLE, A. (coord.), El pañuelo islámico en Europa (cit.). 
nos interesa para nuestro estudio es la diferencia entre aquella indumentaria que tapa el rostro (burka y niqab fundamentalmente) y la que lo deja al descubierto. La primera indumentaria es conocida como velo integral y su tratamiento, en la media en que tapa el rostro de su portado, incita a un mayor conflicto con el orden público. En todo caso, para referirnos a uno u otro tipo, aludiremos al concepto de «velo islámico».

\section{c) Simbolismo religioso}

Antes de entrar a analizar el tratamiento que en los países europeos se le da al velo islámico, conviene detenernos en su consideración práctica que manifiesta la libertad religiosa de las mujeres, así como debatir su consideración como símbolo.

En cuanto a esta segunda cuestión, LÓPEZ-SIDRO LÓPEZ ${ }^{55}$ lo aparta de la consideración de símbolo religioso, al considerarlo de distinta significación a la que podría tener un crucifijo o la estrella de David. Para este autor, elevar el velo islámico a la consideración de símbolo es exagerado, toda vez que ni siquiera queda clara su obligatoriedad. VÁZQUEZ GÓMEZ también coincide en considerar que «la cuestión más controvertida en la actualidad es la de si su uso constituye o no una obligación impuesta por el Corán, debida en parte a la oscuridad con que están formulados los preceptos que lo mencionan. Para algunos es una imposición, mientras que, para otros, tan sólo un consejo o recomendación ${ }^{56}$. En todo caso, no debe menospreciarse la cuestión de considerarlo o no un símbolo religioso, pues su origen y propósitos afectan directamente a la consideración de su uso como práctica amparada por la libertad religiosa. A este respecto, es importantísimo precisar, como hace LÓPEZ-SIDRO LÓPEZ, que solo en la medida que estemos ante una manifestación religiosa podremos concebirlo como admisible, pues toda vez que su porte no sea voluntario quedaría fuera de la tutela del derecho a la libertad religiosa en su dimensión externa, máxime en cuanto atenta contra la dignidad de la mujer ${ }^{57}$. De una u otra forma, es el Tribunal Europeo de Derechos Humanos (TEDH) quien considera al velo islámico como expresión de

${ }^{55}$ LÓPEZ-SIDRO LÓPEZ, Á. «Restricciones al velo integral en Europa y en España: la pugna legislativa para prohibir un símbolo», op. cit., p. 4.

56 VÁZQUEZ GÓMEZ, R., "Aproximación al derecho islámico y su regulación del velo», en Ius Canonicum, 94, 2007, p. 611.

57 LÓPEZ-SIDRO LÓPEZ, Á. «Restricciones al velo integral en Europa y en España: la pugna legislativa para prohibir un símbolo», op. cit.,, p. 5. 
la libertad religiosa en la mayoría de los casos, como veremos. Los valores que se tratan de proteger en el orden europeo son bien distintos de los de aquellos Estados con un radicalismo islámico atenazados para la mujer, de manera que podemos entender que aquí el uso del velo puede ser, a priori y salvo que haya indicios de lo contrario, voluntario y amparado por el derecho a la libertad religiosa, siempre que no traspase los límites que en su momento analizamos.

Procedemos seguidamente a concretar el Estado actual de la cuestión en la España del siglo XXI.

\section{IV.2. Estado actual de la cuestión en España desde el punto de vista normativo}

No existe en nuestro país norma alguna que se pronuncie directamente sobre la cuestión, a diferencia de lo que ocurre en otros países de nuestro entorno europeo, de manera que los conflictos que se han suscitado se resuelven mediante la exégesis del artículo 16 CE junto con el artículo 3 LOLR en la medida que marca de manera abstracta sus límites. En los últimos años se ha suscitado un importante revuelo por la conveniencia de la prohibición del velo integral en espacios públicos, como se ha hecho en otros países europeos. A raíz de ello se estableció la prohibición por parte varias Ordenanzas municipales de civismo y convivencia de algunos Ayuntamientos (Reus, Coín, Lleida y otros municipios), que luego fueron anuladas o suspendidas cautelarmente por resoluciones judiciales. Es especialmente relevante la primera Sentencia del Tribunal Supremo español acerca del velo integral (STS 14 de febrero de 2013), que procederemos a comentar más adelante.

Ya que no existen normas relevantes sobre la cuestión en nuestro país, como hemos señalado, creemos interesante mencionar al menos una cuestión interesante sobre el tema que se suscitó hace unos años en nuestro país. Se trata del RD 1586/2009, de 16 de octubre, por el que se modifica el RD 1553/2005, de 23 de diciembre, el cual regula la expedición del Documento Nacional de Identidad y sus certificados de firma electrónica, y que permite a las mujeres musulmanas hacerse el DNI con el hiyab, siempre que se les vea el rostro con claridad. 


\section{IV.3. Jurisprudencia española en torno al velo islámico}

Vamos a analizar aquí, aunque sea de forma superficial porque no podemos hacerlo de otra forma por problemas de espacio, los supuestos conflictivos más relevantes acontecidos en nuestro país relativos al uso del velo islámico por la mujer y las soluciones a los mismos dadas por los tribunales por cuanto tienen directa relación con el papel de la mujer en el seno de las confesiones religiosas.

\section{Ordenanza de Lleida: Caso WATANI}

Supuesto de hecho: El Ayuntamiento de Lleida acordó en pleno, en el año 2010, la prohibición de portar el velo integral en los espacios públicos, como ya se hiciera en otros países de nuestro entorno. Tras una primera desestimación del recurso presentado ante el Tribunal superior de Justicia de Cataluña (en adelante TSJC), la recurrente, la Asociación WATANI por la libertad y la justicia, presentó recurso de casación ante el Tribunal Supremo (en adelante TS) cuyo objeto era que se declarase nulo el Acuerdo del Pleno del Ayuntamiento de Lleida de 8 de octubre de 2010, por el que se aprueba definitivamente la modificación de tres artículos de la Ordenanza Municipal de Civismo y Convivencia, añadiéndoles nuevos apartados y aprueba inicialmente la modificación de los Reglamentos que regulan el Archivo municipal, el servicio de transporte urbano de pasajeros y el de funcionamiento de los centros cívicos y locales sociales municipales. Goza el proceso administrativo en cuestión de la naturaleza de los procesos para la tutela sumaria de los derechos fundamentales, buscando el amparo de la libertad ideológica y religiosa, contenidos en el artículo $16 \mathrm{CE}$, el derecho a la igualdad, del artículo $14 \mathrm{CE}$ y el derecho de participación en los asuntos públicos, que la recurrente consideraba vulnerados por el acuerdo recurrido. La Ordenanza no se cuestiona en su integridad, sino solo los extremos que afectan al porte del velo integral. Ante tal norma local el TSJC acabó aceptando que el uso del velo integral «es o puede ser manifestación de una creencia o convicción ideológica o religiosa, y por tanto un signo de tal carácter». Adelantamos ya el fallo del TS que, con posición contraria al TSJC, estima el recurso de casación y anula los preceptos de la Ordenanza cuestionada (Sentencia del Tribunal Supremo, Sala de lo Contencioso Administrativo, Sección 7. de 14 de febrero de 2013). Matiza el TS un aspecto relevante para nuestro análisis y es que la Sentencia no responde a la cuestión de si en España cabe o no una prohibición del uso del velo integral en los 
espacios públicos, sino que se mueve en el limitado espacio lógico acotado, "primero, por la especialidad del proceso en que se formuló el recurso y, dentro de él, por los motivos de casación, no teniendo así otro sentido que el de respuesta a la impugnación de una concreta Ordenanza Municipal».

En cuanto a los argumentos, en primer lugar, se centra el Alto Tribunal en considerar que el derecho recogido en el artículo $16 \mathrm{CE}$ queda afectado, lo que ya excluye la competencia de la entidad local para normar en tal sentido. Pero destaca el TS que incluso si la Ordenanza solo regulase de manera accesoria el artículo 16 CE iría en contra del artículo $53 \mathrm{CE}$. Concluye el TS que es preciso atender a la exigencia de una ley previa que establezca el límite para el ejercicio del derecho fundamental de libertad religiosa, como afecta en este caso, pues la prohibición del velo integral supone su afectación. Conviene precisar que la postura del TS en cuanto el porte del velo en transporte público es distinta, ya que su limitación no se refiere tanto al mismo porte sino a la necesidad de acreditación de la identidad para el uso de las tarjetas de transporte. Con todo, el fallo de la Sentencia del TS se predica en el siguiente sentido: «procede la estimación del recurso de casación por vulneración del derecho de libertad religiosa, artículo 16.1 CE, al no existir Ley previa con base a la que pudiera limitarse el ejercicio de tal libertad en lo relativo al uso del atuendo cuestionado [...] excepto en lo referido al Reglamento del Servicio de Transporte Urbano ${ }^{58}$.

Caso en ámbito educativo (NAJWA MALHA): Juzgado de lo Contencioso Administrativo. Sentencia núm. 35/2012 y Tribunal Superior de Justicia de Madrid en apelación

En este caso se le prohibió a una menor (NAJWA MALHA) asistir con velo islámico (no integral, sino hiyab) al instituto en el que estaba matriculada en Pozuelo (Madrid). El artículo 32.4 del Reglamento de Régimen Interior del centro prohíbe el acceso al edifi-

58 La solución dada por el TS casa con lo que ya se expuso cuando abordamos la exégesis de los límites a la libertad religiosa. Como bien significamos en su momento, al abordar las explicaciones del profesor CONTRERAS MAZARIO (CONTRERAS MAZARÍO, J., Derecho y Factor Religioso (cit.)) la libertad religiosa, como integrante de los derechos considerados como fundamentales en virtud de nuestro texto constitucional (artículo $16 \mathrm{CE}$ ), solo puede ser acotado, en cuanto a lo que a su contenido esencial se refiere, ex lege, pues así lo exige el artículo 53.1 CE. El TC en reiteradas sentencias esgrime tal interpretación de reserva de ley como garantía de los derechos considerados fundamentales, A tal efecto vid., entre otras, la STC 83/84, de 24 de julio y STC 140/86, de 11 de noviembre. 
cio con gorras u otras prendas que cubran la cabeza. En base a dicha norma y ante la negativa de la menor de quitarse el pañuelo, la dirección del Instituto le impide el acceso a su aula. Se recurre la situación ante el Viceconsejero de Organización Educativa de la Comunidad de Madrid, que confirmaba la sanción de apartar a la menor. Por ello, se decide recurrir la decisión ante el Juzgado de lo Contencioso Administrativo de Madrid (JCAM en adelante), alegando vulneración del artículo 10.1 de la Constitución, que consagra a la dignidad humana como fundamento del orden político y la paz social, así como del ya conocido artículo $16.1 \mathrm{CE}$. Conviene resaltar, como acertadamente lo hace MORENO ANTÓN ${ }^{59}$, que el artículo 120.2 de la Ley Orgánica 2/2006 de Educación reconoce la autonomía de los centros docentes para aprobar normas de organización y funcionamiento del centro, precepto en virtud del cual, el Instituto de Educación Secundaria "Camilo José Cela», en el que está escolarizada NAJWA, tiene un Reglamento de Régimen Interior aprobado por el Consejo escolar con fecha 30 de octubre de 2007, cuyo artículo $32^{60}$ impide acudir con, entre otros atuendos, el velo islámico. Resuelve el JCAM considerando, en primer lugar, y en cuanto a la dignidad alegada ex artículo $10 \mathrm{CE}$, que «No cabe hablar de vulneración del principio de dignidad de la persona, por el mero hecho de prohibirle acudir a clase con la cabeza cubierta por ningún tipo de prenda, sino que se trata de una norma de convivencia en cuanto a la indumentaria a utilizar por todos los alumnos con objeto de evitar distracciones a sus compañeros y para regular la convivencia en el centro docente mediante la delimitación de una conducta que todo alumno conoce, con carácter previo, y está obligado a respetarla y en virtud de la autonomía para elaborar y aprobar normas de organización y funcionamiento del centro» (FJ 5). Rechazado el argumento de la dignidad humana, continúa el Juzgado con la posible conculcación del derecho a la libertad religiosa, para lo que trae a colación la teoría sobre sus límites, analizando el artículo 3.1 LOLR que ya hemos tratado al inicio de nuestro estudio. La interpretación de los límites la desarrolla conforme a la doctrina del TEDH, la cual ya ha sido tratada anteriormente. Al hilo de tal argumentación, acaba desestimando el juzgador, asimismo, la vulneración del artículo $16 \mathrm{CE}$. Con todo, acaba desestimando el recurso. Frente a esta Sentencia, los padres de NAJWA interponen recurso de apela-

${ }^{59}$ MORENO ANTÓN, M., "Hiyab y escuela en España: un supuesto de gestión excluyente de la diversidad», Revista latinoamericana de Derecho y religión, Vol. 2, núm. 1, 2016, pp. 1.-25.

60 Señala la disposición del Instituto que «en el interior del edificio no se permitirá el uso de gorras ni de ninguna otra prenda que cubra la cabeza».

(C) UNED. Revista de Derecho UNED, núm. 23, 2018 
ción ante el Tribunal Superior de Justicia de Madrid (TSJM), que es rechazado por la sentencia 129/2013, de 8 de febrero de 2013. El TSJM no entra en el fondo del asunto, limitándose a analizar una cuestión procedimental, la posible inadmisión del recurso por razón de la cuantía ${ }^{61}$.

Caso abogada: Tribunal Supremo (Sala de lo ContenciosoAdministrativo, Sección 8. ${ }^{a}$ ) Sentencia de 2 de noviembre de 2010

Se presenta recurso ante el TS frente a la desestimación del Consejo General del Poder Judicial (CGPJ) del recurso interpuesto contra acuerdo verbal del Presidente de la Sala de lo Penal de la Audiencia Nacional de 29 de octubre de 2009 de ordenar a la recurrente, letrada, que abandonara el estrado de los abogados por llevar un pañuelo sobre su cabeza. La recurrente, solicitaba al Tribunal que «[d] icte sentencia declarando que el acuerdo verbal impugnado de sacar a la recurrente del estrado de los letrados por el mero hecho de portar el pañuelo islámico o hiyab constituye una vulneración de los derechos fundamentales invocados y es por tanto nulo». La abogacía del Estado, en igual sentido que el fiscal, se opuso al planteamiento de la recurrente abogando por la inadmisión del recurso o, subsidiariamente, su desistimiento. La defensa de la recurrente se basó en considerar vulnerado el artículo 16 de la CE porque la prohibición de usar el hiyab supone «una intromisión no autorizada por la ley en el ámbito de la libertad religiosa». Asimismo, el derecho a no ser discriminada ha sido vulnerado según la demanda porque la recurrente se considera discriminada en relación con sus compañeros vestidos con toga que no fueron molestados mientras que ella sí lo fue por un factor que legalmente no le puede causar perjuicio, pues, el artículo 39.1 del Estatuto General de la Abogacía subraya que se limita a exigir la toga, la cual portaba. Además, se consideraba lesionada en su derecho al respeto a la vida privada porque «iba vestida en consonancia con sus convicciones religiosas o culturales" (artículo 18 CE y 8 CEDH) (FJ 3). El TS no llegó a entrar en el fondo del asunto, al considerar que el caso, que se refería a un acuerdo tomado en el ejercicio de la policía de estrados (ex artículo 684 LECRIM y 587 LOPJ), era de naturaleza jurisdiccional y no gubernativa, y por tanto no correspondía al CGPJ revisarlo, de modo que éste tendría que haber emitido una resolución expresa de inadmisión.

${ }^{61}$ MORENO ANTÓN, M., «Hiyab y escuela en España: un supuesto de gestión excluyente de la diversidad», op. cit., p. 20. 
Caso en ámbito laboral: Juzgado de lo Social de Palma de Sentencia núm. 31/2017 de 6 febrero

Comentamos ahora una muy reciente sentencia, del mes de febrero del año 2017, que vuelve a tratar el tema del uso del velo islámico, no integral, sino el hiyab, esta vez en el ámbito laboral. La trabajadora demandante presta servicios en el departamento de servicio al pasajero de una compañía aérea y por tanto de cara al público. Solicitó hacer uso del velo islámico como expresión de su sentimiento religioso, lo que inicialmente le fue autorizado por la empresa de forma provisional y después negado bajo la invocación de las exigencias de uniformidad y la imagen corporativa de la empresa para justificar dicha negativa. La trabajadora, aun así, manteniendo la comunicación con la empresa a los efectos de aclarar la situación, vino haciendo uso del velo islámico en distintas ocasiones, en resistencia a las instrucciones de la empresa, que llegó a sancionarle hasta en siete ocasiones, lo que, en procedimiento de impugnación de dichas sanciones, nos habrá de llevar a efectuar la debida ponderación con el derecho fundamental a la libertad religiosa, a los efectos de determinar si estaban justificadas las medidas adoptadas por la empresa (FJ 3). Tras analizar los límites a la libertad religiosa, ya estudiados en el presente trabajo, la Sentencia concluye, a diferencia de las resoluciones que hemos comentado más arriba, que: "[E]n el supuesto examinado cabe resolver el conflicto planteado considerando que el uso del hiyab es una manifestación de la creencia religiosa de la trabajadora, que la empresa no mantiene ninguna politica de neutralidad religiosa obedeciendo la prohibición impuesta a aquélla a una exigencia meramente estética, que no es comparable el uso de meros adornos a la utilización en este caso del velo, y que no se ha siquiera invocado ni acreditado por la empresa la causación de perjuicio alguno en su imagen derivado del uso del hiyab, sin que además hubiera en la empresa norma prohibitiva alguna, pues el manual de imagen personal y uniformi$\mathrm{dad},[. .].[\mathrm{y}]$ con estas consideraciones, resolverlo a favor del derecho de la trabajadora, estimando producida la discriminación invocada y la consiguiente lesión de su derecho a la libertad religiosa, dejando por ello sin efecto las sanciones impuestas» (FJ 8). Sin poder realizar una interpretación demasiado profunda, diremos que aplica los mismos criterios ya comentados en las otras resoluciones pero aquí, a diferencia de en el resto, no considera que pueda quedar limitado el derecho a la libertad religiosa. En definitiva, el Juzgado de lo Social número 1 dio la razón a Ana Saida Rodríguez, la trabajadora de Acciona en Son Sant Joan que había demandado a su 
empresa por prohibirle llevar el velo, permitiéndole ir con velo a su puesto de trabajo. El Juzgado de lo Social de Palma permitió a Ana ir a su puesto de trabajo con su hiyab y suspendió las sanciones que le habían sido impuestas: la empresa debía indemnizar a la trabajadora así como devolverle el dinero que había dejado de pagarle por las suspensiones de empleo y sueldo que le habían aplicado. Eso sí, esta Sentencia no es firme y puede ser recurrida.

\section{DISTINTAS POSIBLES DISCRIMINACIONES EN EL ÁMBITO RELIGIOSO}

Finalmente, vamos a pasar a analizar otras distintas y también importantes posibles discriminaciones de la mujer que existen en el ámbito del pluralismo religioso, a saber, los delitos de odio por razón de género en el ámbito religioso, el acceso a los puesto de autoridad eclesiástica por parte de las mujeres en las distintas confesiones religiosas, la mutilación genital femenina...

\section{V.1. Delitos de Odio por razón de género en el ámbito religioso}

Ahora sí, nos encontramos ante el epígrafe núcleo fundamental de nuestro trabajo. En base a todo lo que se ha venido analizando, la figura de la mujer precisa de una especial protección por parte del ordenamiento jurídico si se quiere soslayar o, al menos, paliar, la discriminación por razón de género, e incluso la violencia de igual naturaleza en cualquiera de sus formas. Evidentemente, toda medida normativa que se adopte en este contexto atañe al papel ad intra de la mujer en las confesiones, si bien deben tenerse presente las consecuencias que derivan del derecho a la libertad religiosa.

Así, en vista a la posición de la mujer en la Iglesia manifestada en el apartado 3, pueden entrar en conflicto, por un lado, la dignidad y salvaguardia de la mujer y, por otro, el derecho a desarrollar prácticas que pueden afectar a la esfera jurídica femenina pero que, prima facie, pueden estar amparadas bajo el paraguas de la libertad religiosa. Esta pugna no puede ser resuelta sino atendiendo a los límites que restringen la libertad religiosa, de ahí la importancia que le dimos en su momento al estudio de tales límites (vid. Supra. epígrafe 2.2.b).

Al hilo de lo anterior, y en base a una interpretación elemental de nuestro sistema normativo, con especial atención al ordenamiento 
jurídico-penal, se pone de manifiesto que todas las conductas que se consideren especialmente gravosas frente a los bienes jurídicos especialmente protegidos, esto es, aquellas conductas constitutivas de delito, quedarán fuera del ámbito de justificación que otorga el derecho a la libertad religiosa ${ }^{62}$.

En esta sede de intervención del Derecho penal podemos destacar, como así lo hace SOUTO GALVÁN ${ }^{63}$, la actual configuración del delito de odio recogido en el artículo 510 del Código penal (CP), cuya modificación en julio de 2015 amplió su campo de actuación a aquellos discursos al odio por razones de género. Es evidente que la tipificación del delito en lo que respecta al género no es de exclusiva aplicación en el ámbito religioso, sin embargo, sí ha sido en este campo en el que se han suscitado los casos más polémicos ${ }^{64}$.

a) Imán de Fuengirola: Sentencia del Juzgado de lo Penal de Barcelona, Sentencia de 12 de enero de 2004

Hasta el momento, el único caso que ha acabado con sanción penal a consecuencia de cometer el delito previsto en el artículo $510 \mathrm{CP}$ por razón de género, trae causa en la publicación de un libro titulado "La mujer en el Islam», cuyo autor, MOHAMED K.M., ejerció tareas de imán en España desde 1984. El libro aborda una interpretación excesivamente machista del Corán, incluyendo comentarios entre los que justificaba el maltrato físico a la mujer si no se consigue dominar a ésta en el ámbito familiar, propugnando por un total sometimiento de la figura femenina, considerándolo como algo natural ${ }^{65}$. Considera la Sentencia (FJ 2) que se excede del campo de actuación que le permite la libertad religiosa, en cuanto que «en el ejercicio de su libertad el acusado diserta sobre la mujer en

${ }^{62}$ Interpretación restrictiva del ámbito de actuación del Derecho penal por ser éste fragmentario. A este respecto vid. MUÑOZ CONDE, F. y GARCÍA ARÁN, M., Derecho penal, parte general, Tiran lo Blanch, Valencia, 9. ${ }^{\circ}$ ed., 2015, pp. 79-80.

${ }^{63}$ Vid., SOUTO GALVÁN, B., "Discurso del odio: Género y libertad religiosa», op. cit., pp. 2 y ss.

${ }^{64}$ SOUTO GALVÁN, B., en «Discurso del odio: Género y libertad religiosa», op. cit., p. 20: «Este marco de análisis del referido delito pone en tela de juicio la confluencia entre: -por un lado, y como bien jurídico protegido, la igualdad y el derecho a no ser discriminado, acotándolo para el caso de igualdad de género; - por otra parte, pugnará por su vigencia el derecho fundamental a la libertad de expresión (artículo 20 CE); - sin perder de vista, asimismo, el derecho a la libertad religiosa (artículo 16 CE), en la medida en que pueda amparar tales conductas cuando se escapen de los límites de protección de la norma penal».

${ }^{65}$ Extractos literales del libro. Pueden consultarse en el hecho probado $2 .^{\circ}$ de la sentencia.

(C) UNED. Revista de Derecho UNED, núm. 23, 2018 
muy diferentes aspectos algunos de nula vinculación con la religión en las sociedades con culturas cristianas, [...] estando toda la obra presidida por un tono de machismo obsoleto, en algunos casos muy acentuado, discordante con el principio de igualdad recogido en el artículo 14 de la CE y que fundamenta la afirmación de las acusaciones de que el libro en algunos párrafos vulnera abiertamente dicho principio promoviendo conductas de discriminación por razón de sexo intolerables y penalmente reprochables». La sentencia, en base a lo anterior, además de analizar los elementos del tipo penal, lo que escapa de nuestro estudio, condena al Imán por considerar que, «esa confrontación entre el derecho a la libertad religiosa en su dimensión externa, ejercitado por Mohamed, y el derecho a la integridad moral de la mujer destinataria de su discurso, debe resolverse en favor de este último por cuanto actúa de límite de aquél, [...] y como, cuando de la colisión entre el derecho a la libertad de expresión vinculado a la libertad ideológica y el derecho al honor se trata, [acaba] convirtiendo la conducta del acusado, al redactar, publicar y difundir el capitulo del libro dedicado a los malos tratos, en reprochable conforme al artículo citado al inicio del primer fundamento».

\section{b) Imán de Terrassa}

Otro caso muy similar al anterior es el de un Imán de Terrassa, actualmente encausado en un proceso que, en fase de instrucción, investiga la Fiscalía Provincial de Barcelona de Servicio de Delitos de Odio y Discriminación, al hilo de supuestos mensajes discriminatorios y vulneradores del principio de igualdad y del derecho a la integridad física y moral de la mujer, pronunciados con ocasión de los sermones que predica ante los fieles que asisten a la mezquita los viernes al mediodía, el día de la semana de referencia del colectivo musulmán y que congrega el volumen de fieles más elevado en la mezquita. En la querella, presentada ante el juez decano de Terrassa, el fiscal de Delitos de Odio y Discriminación en Catalunya, Miguel Ángel Aguilar, acusa al Imán de incitar a la violencia contra la mujer. No existe aún condena alguna para el Imán.

\section{c) Obispo de Alcalá de Henares}

En esta ocasión, la Asociación «Tertulia Feminista Les Comadres» se querelló contra un Obispo por comparar el aborto con el genocidio nazi. La querella se interpone por considerarles respon- 
sables de la comisión de un delito continuado de injurias graves, así como del delito de provocación al odio, la discriminación o la violencia del artículo $510 \mathrm{CP}$, en este caso concreto por razones de género ${ }^{66}$. Sin embargo, en esta ocasión la querella ni siquiera fue admitida a trámite. En concreto, el Auto del Juzgado de Instrucción número 6 de Alcalá de Henares de 10 de julio de 2012, en su FJ 3, consideraba que «las palabras del Obispo no se encuadran en ninguno de los supuestos tipificados en el artículo 510 del Código Penal, y con sus alusiones a evitar cualquier discriminación injusta, se encuentran "amparadas por la libertad de expresión y la libertad religiosa" ${ }^{67}$.

\section{d) Consideraciones a los casos anteriores}

Aunque somos de la opinión de que el artículo 510 del Código Penal ha sufrido una importante transformación a través de la reforma operada en el año 2015, entre otros motivos, al añadir a la circunstancia basada en razones de sexo, la fundada en motivos de género, entendemos que dicha reforma de este tipo penal no solventaba del todo los problemas que generaba su versión previa. No obstante esto, coincidimos con SOUTO GALVÁN en que sí nos resulta procedente la inclusión de esta nueva circunstancia, más adecuada que la basada en el sexo para reprimir la incitación al odio y la violencia por razones de género ${ }^{68}$.

Nos resulta de especial interés para nuestro estudio traer a colación estos casos, en tanto en cuanto los sujetos que han promulgado los discursos relacionados con este delito son autoridades eclesiásticas en sus respectivas confesiones. Además, es manifiesta la importancia de contextualizar la situación en la que se ejerce el derecho a la libertad religiosa en su manifestación externa, como reiterada-

${ }^{66}$ Ibid., p.35.

${ }^{67}$ LÓPEZ-SIDRO LÓPEZ, Á., «La libertad de expresión de la jerarquía eclesiástica y el discurso del odio", Revista General de Derecho Canónico y Derecho Eclesiástico del Estado, número 42, octubre 2016, p. 8.

${ }^{68}$ Vid., RUEDA MARTÍN, M.A., La violencia sobre la mujer en su relación de pareja con un hombre, Ed. Reus, Madrid, 2012, p. 51, ALCALE, M., La discriminación hacia la mujer por razón de género en el Código Penal, Madrid, 2006, p.68 y SOUTO GALVÁN, B., en «Discurso del odio: Género y libertad religiosa», op. cit., p. 40. Entendemos, como esta última autora, que «la diferencia fundamental entre ambos conceptos es que la circunstancia referida al sexo hace referencia a la mujer por ser mujer, es decir, basada en un fenómeno puramente biológico, mientras que el motivo basado en razones de género englobaría los discursos realizados contra las mujeres por el papel que tradicionalmente la sociedad se ha encargado de otorgarle. El efecto de ambos discursos sería la discriminación pero el fundamento pasa de ser meramente biológico a estar basado en construcciones sociales». 
mente venimos insistiendo durante todo este estudio, pues si hubiese acontecido el discurso del Imán de Fuengirola en un Estado de marcada tradición islámica, probablemente no hubiera tenido sanción penal; del mismo modo que, en otros Estados con ideas más liberales, sí que hubiese tenido sanción el discurso contrario al aborto por parte del Obispo del caso c), por lo que los límites a la libertad religiosa dependen sobremanera del contexto.

\section{V.2. Acceso a los puestos de autoridad eclesiástica en las distintas confesiones}

En la vida de las mujeres ya sean creyentes o no creyentes, la religión continúa jugando un papel importante, bien directamente bien a través de su influencia tradicional en la sociedad o el Estado. En el caso de las religiones, como bien es sabido, bajo el argumento de un orden divino y superior, se transmiten unos estereotipos de género basados en la superioridad del hombre sobre la mujer, propios de una cultura patriarcal, que ha llevado a un tratamiento discriminatorio hacia ellas, otorgándole un papel muy marcado como esposa, madre y ama de casa. Esto se refleja también en la discriminación hacia las mujeres en la forma de contar las religiones su origen e historia, en las normas que le impiden acceder a jerarquías de poder y a oficiar ciertos ritos, y a cumplir determinados códigos sobre comportamiento y vestimenta. La mayoría de las religiones se configuran patriarcalmente y acceden con dificultad a puestos de responsabilidad en las comunidades religiosas. El poder es ostentado por los hombres y a las mujeres solo le queda acatar su voluntad. Existen distintas formas de violencia de género hacia las mujeres, que son justificadas en el nombre de la costumbre o la religión y que impiden el acceso y el disfrute por parte de las mujeres de sus derechos humanos básicos.

\section{V.3. La mutilación genital femenina}

En nuestra opinión, resulta evidente que la protección de la diversidad religiosa (o cultural) debe ceder cuando se trata de la violencia contra la mujer. La violencia aplicada a las mujeres por el hecho de serlo no puede ser parte de ninguna identidad nacional, étnica o religiosa. Son muchos los lugares del mundo en los que, desgraciadamente, todavía perviven prácticas tradicionales y culturales que se llevan a cabo en el seno de la familia, que vulneran los derechos de las mujeres y que resultan gravemente perjudicia- 
les para su salud. Entre dichas prácticas se encuentra, por ejemplo, la mutilación genital ${ }^{69}$, que resulta especialmente cruel por varios motivos y que no puede ser aceptada desde ningún punto de vista. Esta es la posición adoptada en el seno de la Organización de Naciones Unidas. La Declaración sobre la Eliminación de la Violencia contra la Mujer de 1993 prohíbe a los Estados invocar la costumbre, la tradición o consideraciones religiosas para evadir la obligación de prevenir, investigar y castigar los actos de violencia contra la mujer (artículo 4..$^{\circ}$. De la misma forma, la Plataforma de Acción de la Cuarta Conferencia Mundial sobre la Mujer celebrada en Beijing en 1995 indicó que los Estados deben «condenar la violencia contra la mujer y refrenarse de invocar cualquier costumbre, tradición o argumento religioso para evitar sus obligaciones con respecto a su eliminación como establece la Declaración de la Eliminación de la Violencia contra la Mujer». Agregó que deben «Adoptar medidas urgentes para combatir y eliminar la violencia contra la mujer, que constituye una violación de los derechos humanos, derivada de prácticas nocivas relacionadas con la tradición o la costumbre, los prejuicios culturales y el extremismo». En definitiva, por tanto, y con lo que acabamos de señalar, resulta posible atisbar el interesante problema de fondo que se observa alrededor de esta cuestión: la duda de si nos encontramos ante unas prácticas de trasfondo y tradición político-cultural o religioso. A este respecto hay opiniones para todos los gustos ${ }^{70}$.

La manipulación del argumento cultural es particularmente evidente cuando se trata de la religión. En muchas ocasiones se legitiman prácticas violatorias de los derechos de las mujeres debido a que están prescritas por el texto sagrado y, por tanto, son ordenadas por Dios, cuando en realidad no están en él o se derivan de una interpretación del texto sagrado. A lo que se debe añadir el hecho de que, en la mayoría de las religiones, por no decir en su totalidad, las mujeres han estado excluidas «de la elaboración doctrinal, de los puestos de

${ }^{69}$ Interesante resulta, a este respecto, la descripción de los tipos de mutilación genital que existen que hace LA RELATORA ESPECIAL DE LAS NACIONES UNIDAS SOBRE LA VIOLENCIA CONTRA LA MUJER, SUS CAUSAS Y CONSECUENCIAS, en su Informe del año 2002 sobre «Las prácticas culturales dentro de la familia que entrañan violencia contra la mujer». Empieza señalando: «(...) Los métodos y tipos de mutilación difieren según el país y el grupo étnico que lo realiza (...)».

70 Vid., entre otros, CONTRERAS MAZARÍO, J.M.: «Globalización, derechos humanos y prácticas tradicionales en el ámbito de la familia. Especial referencia a las actividades de las Naciones Unidas», Globalización y Derecho, Editorial Colex, Madrid, 2003 y GARCÍA RUIZ, Y.: «Pluralidad religiosa, diversidad cultural y derechos de la mujer: Novedades jurisprudenciales en España», op. cit., pp. 325-348. 
responsabilidad y del espacio sagrado ${ }^{71}$, lo que sin duda favorece una interpretación sexista de los textos sagrados. Ejemplo de esto que decimos es el caso de la muerte por lapidación como castigo al adulterio, que se ha aplicado en la mayoría de las ocasiones contra mujeres; en este caso, el Corán no ordena este castigo, sino que ha sido prescrito gracias a la labor interpretativa de los ulemas. Es más, el castigo de la lapidación había desaparecido hasta hace pocas décadas y sólo en algunos países islámicos, no en todos, se ha reimplantado recientemente (Irán, Pakistán, Arabia Saudí, Sudán, Afganistán, el norte de Nigeria). Algo similar sucede con las mutilaciones genitales femeninas y los crímenes de honor, practicados en algunos países islámicos. Así mismo, el Corán señala que sus fieles deben vestir decentemente, pero en ningún momento menciona que las mujeres tienen que cubrirse el cabello, la cabeza o la cara. A pesar del interesante debate planteado opinamos que es irrelevante, para la búsqueda de una solución a los conflictos planteados, cual sea el origen o trasfondo del que procedan estas situaciones.

Con todo lo visto, resulta claro que algunos ritos ancestrales que traen incluidos como tradiciones algunas religiones (que no siempre y en todos los supuestos está claro que provengan y/ o se deban incluir en la actualidad en el ámbito religioso en puridad sino en tradiciones culturales antiguas mantenidas por distintos motivos personales en la actualidad) y que hoy en día siguen produciéndose, no pueden tener cabida en la sociedad plural en que vivimos. Entendemos pues que tenemos que intentar encontrar una solución a las situaciones de desigualdades de las mujeres dándonos igual si su trasfondo es político-cultural o religioso: a todas ellas y no sólo a las que supongan la comisión de un delito, porque estas situaciones ya tienen claramente establecida su penalización. Respecto a las que no están penadas, opinamos que habría que exigir a los Estados, y en nuestro caso concreto al Estado español, que lleve a cabo determinadas actuaciones para garantizar la universalidad de los derechos de las mujeres en el marco de las religiones. Aunque, como ya se ha apuntado anteriormente, la apuesta del Derecho Internacional es clara a favor de los derechos de las mujeres cuando éstos se enfrentan al respeto de la diversidad religiosa o cultural ${ }^{72}$, la solución de es-

${ }^{71}$ BRAMON, D.: Ser mujer y musulmana, Biblioteca del Islam Contemporáneo, España, Bellaterra, 2006, p. 123.

72 Vid.: El Pacto Internacional de Derechos Civiles y Políticos reconoce el derecho a la igualdad entre hombres y mujeres (artículo 13) y el derecho a la igualdad en el matrimonio (artículo 23) pero también reconoce la libertad religiosa (artículo 18) y el respeto a la diversidad cultural y religiosa (artículo 27). La Convención para la Eliminación de todas las formas de Discriminación contra la Mujer (cedaw, por su sigla en 
tos conflictos no es tan sencilla. Lo que sí está claro, en nuestra opinión, es que se debe desechar la opción de dar una única respuesta, de todo o nada, para todos los conflictos de este tipo. Además de esto y de la señalada diferenciación entre el hombre y la mujer en las confesiones religiosas, también hay que tener en cuenta como factor importante al estudiar estas teóricas situaciones de desigualdad la diferente posición de las propias mujeres pertenecientes o practicantes de una misma religión: no se puede asumir que un determinado concepto de igualdad o de derechos es compartido por todas las mujeres del mundo. A este respecto hay quien ha afirmado, muy acertadamente en nuestra opinión: "Incluso dentro de una misma nación, etnia o religión existen divergencias entre las posiciones de las mujeres porque la cultura y la religión no afectan de igual manera la vida de todas las mujeres: también existen componentes sociales, económicos y geográficos que inciden en su estatus $\rangle^{73}$. Opinamos, en esta línea, que la visión de lo que debe ser la igualdad sexual o los derechos de las mujeres debe considerar necesariamente las diferencias que existen entre las mismas mujeres debido a la raza, la posición social y económica, el origen nacional, la orientación sexual, entre otros. Las mujeres también tienen derecho al respeto de su diversidad y su autonomía no puede ser anulada bajo la idea de una «libertad impuesta ${ }^{74}$.

inglés) toma partido por uno de los extremos de este conflicto, obviamente por los derechos de las mujeres. En el artículo 5. ${ }^{\circ}$, numeral a, obliga a los estados parte a tomar todas las medias apropiadas para «a) Modificar los patrones socioculturales de conducta de hombres y mujeres, con miras a alcanzar la eliminación de los perjuicios y las prácticas consuetudinarias y de cualquier otra índole que estén basados en la idea de la inferioridad o superioridad de cualquiera de los sexos o en funciones estereotipadas de hombres y mujeres» y en el artículo 2. ${ }^{\circ}$, literal f, indica que "Los Estados Partes condenan la discriminación contra la mujer en todas sus formas, convienen en seguir, por todos los medios apropiados y sin dilaciones, una política encaminada a eliminar la discriminación contra la mujer y, con tal objeto, se comprometen a: (...) f) Adoptar todas las medidas adecuadas, incluso de carácter legislativo, para modificar o derogar leyes, reglamentos, usos y prácticas que constituyan discriminación contra la mujer». Más explícita aún es la Declaración y el Programa de Acción de Viena producidos en el marco de la Conferencia de las Naciones Unidas sobre Derechos Humanos celebrada en Viena en 1993. Esta defendió «(...) la erradicación de cualquier conflicto que pueda surgir entre los derechos de las mujeres y los efectos perjudiciales de ciertas prácticas tradicionales o consuetudinarias, prejuicios culturales y extremismo religioso".

${ }^{73}$ ARDILA TRUJILLO, M.: «Hacia la resolución de los conflictos entre la protección de la diversidad cultural y el reconocimiento de los derechos de las mujeres», op. cit., pp. 137-152.

${ }_{74}$ Ejemplos de esto que comentamos: 1. Cómo en la década de los setenta, en contraste con las demandas de las feministas blancas de clase media que pedían el desmantelamiento de la institución de la familia nuclear por ser un elemento clave en la opresión de la mujer, las feministas indígenas y afroamericanas argumentaban que para ellas la libertad consistía en poder formar una familia, puesto que la larga historia de esclavitud, genocidio y racismo había operado precisamente rompiendo sus comunidades y sus familias; 2 . El uso del denominado velo islámico anteriormente analizado.

(c) UNED. Revista de Derecho UNED, núm. 23, 2018 


\section{CONCLUSIONES A LA VISTA DE LAS SOLUCIONES DOCTRINALES Y JURISPRUDENCIALES ANALIZADAS}

Para terminar, vamos a tratar de plantear aquello que, a nuestro entender, pueda ser exigible a los Estados, y más concretamente al Estado español, para garantizar la universalidad de los derechos de las mujeres en el marco de las religiones.

Como se ha podido comprobar a lo largo de la exposición de nuestro trabajo, el debate entre si debe primar la libertad religiosa o se deben superponer los límites de ésta no resulta fácil. Y no solo no resulta fácil en la medida en que limitemos a un sujeto el obrar como considere en base a sus creencias, sino también en la medida en que pretendamos que el Estado se inmiscuya en el seno de una confesión. En cuanto a esto último, consideramos, como dice MARTÍNEZ TORRÓN ${ }^{75}$, que no debe el Estado adentrarse en la autonomía de la Iglesia salvo que la confesión en cuestión atente claramente frente a la moralidad pública o el orden público. Trasladado al campo de nuestro estudio, el papel de la mujer, coincidimos con MARTÍNEZ TORRÓN en que se debe buscar que la religión no sea utilizada como instrumento de predominio del varón en la vida civil de la mujer, es decir, evitar que sirva como justificación para discriminar a la mujer. Desde luego, así se ha puesto de manifiesto cuando hemos comentado la tipificación del artículo 510 CP y así mismo lo poníamos de manifiesto en otra de nuestras publicaciones anteriores sobre esta temática hace dos años cuando indicábamos: «En nuestra opinión, el Estado tiene la obligación de prevenir y proteger contra aquellas prácticas que lesionen a las mujeres acudiendo a la capacitación, a medidas legislativas y de sustitución de las prácticas discriminatorias, al diálogo con los dirigentes religiosos... entre otras estrategias. Consideramos que todo Estado como el nuestro debe ir en la línea de actuación de no permitir que la libertad religiosa sea la vía para negar a las mujeres el derecho a construir y ejecutar un proyecto de vida en condiciones de igualdad. Para que la libertad de religión no sea contraria a los derechos de la mujer es indispensable que el derecho a la diferencia implicado por esa libertad no se entienda como un derecho a la indiferencia ante la condición de la mujer» ${ }^{76}$.

${ }^{75}$ MARTÍNEZ-TORRÓN, J., La igualdad de sexos (cit.), p. 67.

${ }^{76}$ Vid., PAREJO GUZMÁN, M.J., «Resolución de conflictos entre la diversidad religiosa y los derechos de las mujeres en España», Laicidad y Libertades. Escritos Jurídicos, n. 15, 2015, pp. 189-209. 
En este punto conclusivo vamos a volver a señalar lo que hemos mencionado anteriormente de que, además de la señalada diferenciación entre el hombre y la mujer en las confesiones religiosas, también hay que tener en cuenta, como factor importante al estudiar estas teóricas situaciones de desigualdad, la diferente posición de las propias mujeres pertenecientes o practicantes de una misma religión, cuestión a la que también nos referíamos ya en esa otra de nuestras publicaciones anteriores sobre el tema y respecto de la cual concluíamos que "no se puede asumir que un determinado concepto de igualdad o de derechos es compartido por todas las mujeres del mundo. Las mujeres también tienen derecho al respeto de su diversidad y su autonomía no puede ser anulada bajo la idea de una "libertad impuesta" ${ }^{77}$.

Refiriéndonos a las limitaciones a la dimensión externa de la libertad religiosa en cuanto estas afecten a la mujer, fundamentalmente en cuanto al uso del velo, deben resaltarse varias conclusiones importantes. En primer lugar, no es nuestro objetivo analizar el fundamento de portar el velo islámico, eso es trabajo de los teólogos. Nuestro propósito es, en cambio, analizar la situación desde una perspectiva jurídica siendo consecuentes en todo momento con el artículo $16 \mathrm{CE}$, el cual ampara la libertad religiosa y de conciencia, por lo que la llevanza del velo islámico hemos de considerarla amparada en tal precepto, toda vez que no se demuestre que su porte es una imposición contraria, precisamente, a su conciencia. Pero, en todo caso, no podemos presumir que una mujer lleve el velo contrariamente a su voluntad, aunque, en el caso que así se demuestre, no estaremos, desde luego, bajo el paraguas de la libertad religiosa ${ }^{78}$. En segundo lugar, en nuestra opinión, conviene precisar ante qué tipo de velo nos encontramos para resolver la cuestión: a) Analizando primeramente el velo no integral, hemos de mostrar nuestra opinión contraria a la resolución por el JCAM, toda vez que justifica la prohibición del velo en base al carácter aconfesional de nuestro Estado. Nos posicionamos a favor de la interpretación de

77 Vid., PAREJO GUZMÁN, M.J., «Resolución de conflictos entre la diversidad religosa y los derechos de las mujeres en España», op. cit., pp. 189-209.

${ }_{78}$ Al hilo de ello, es interesante la consideración de LOPEZ SIDRO en cuanto que para éste, «lo que se puede juzgar de las creencias - más allá del campo de la teología - no es su mayor o menor acierto o razonabilidad, sólo su posible vulneración del orden público»: LÓPEZ-SIDRO LÓPEZ, Á. "Restricciones al velo integral en Europa y en España: la pugna legislativa para prohibir un símbolo», op. cit., p. 41.

(c) UNED. Revista de Derecho UNED, núm. 23, 2018 
LÓPEZ-SIDRO LÓPEZ ${ }^{79}$ y MORENO ANTÓN ${ }^{80}$, quienes consideran que la laicidad no puede esgrimirse como límite a la libertad religiosa como parece pretender concluir la sentencia en cuestión, al igual que la mayoría de las resoluciones del TEDH. En efecto, como dijimos al plantear el marco jurídico, basándonos en los estudios de CONTRERAS MAZARÍO ${ }^{81}$, la laicidad «implica velar por el reconocimiento, tutela y promoción del derecho a la libertad de conciencia y religiosa»; b) En relación al velo integral la cuestión sí me merece una respuesta distinta. Ahora sí que debemos tener presente el orden público consagrado como límite del 16.1 CE y 9.1 CEDH. $\mathrm{Al}$ respecto, abogamos por limitar la utilización de esta prenda que evita que veamos el rostro de su portador y ello porque dificulta sobradamente la labor de las autoridades que velan por nuestra protección, así como de cualquiera de nosotros que nos relacionemos con su portador. Al impedir conocer con quién llevamos a cabo esa relación en el tráfico jurídico, pone en serio riesgo los valores de nuestra sociedad occidental. Sin embargo, no compartimos la argumentación que añade ARECES PIÑOL ${ }^{82}$, quien, además de emplear el argumento de la seguridad pública, se refiere a la dignidad de la mujer como cortapisa del velo integral. Al respecto nos mantenemos en lo que expusimos al principio de este epígrafe de que cada mujer deberá decidir qué es acorde a su dignidad y qué no y nosotros, salvo que se demuestre lo contrario, no podemos presumir que la prenda sea portada contra su voluntad y no en base a sus creencias, por muy ostentosa que sea aquella.

En relación a esta cuestión del papel de la mujer en las distintas confesiones religiosas y su posible discriminación en las mismas por cuestiones como, por ejemplo, la que hemos venido analizando del uso del velo, GARCÍA VÁZQUEZ recurre ${ }^{83}$, junto a otros autores como FERREIRO GALGERA, al término y concepto de «la integración». FERREIRO GALGUERA señala que «es indudable que al llevar un burka o un niqab la mujer está amputando su

79 LÓPEZ-SIDRO LÓPEZ, Á. «Restricciones al velo integral en Europa y en España: la pugna legislativa para prohibir un símbolo», op. cit., p. 41.

${ }^{80}$ MORENO ANTÓN, M., «Hiyab y escuela en España: un supuesto de gestión excluyente de la diversidad», op. cit.

${ }_{81}$ CONTRERAS MAZARÍO, J., Derecho y Factor Religioso (cit.), p.83.

82 ARECES PIÑOL, M.T., "¿El velo integral, burka y niqab, queda amparado por el legítimo ejercicio de la libertad religiosa?», Revista General de Derecho Canónico y Derecho Eclesiástico del Estado, n. ${ }^{\circ}$. 26, 2011, p. 36.

${ }^{83}$ En GARCÍA VÁZQUEZ, S., El derecho a la libertad religiosa y el uso del velo islámico... cit., p. 394-397. 
posibilidad de relación con los demás y, por tanto, su capacidad de crecer como ser social» ${ }^{84}$.

Para todos los casos, y por último, apelamos a la necesidad de legislar las soluciones que se consideren convenientes, pues no olvidemos que, actualmente, como hemos indicado, la solución carece de agarre legal, al menos directamente, en nuestro país. Como dijimos al inicio, el Derecho está para regular conflictos de intereses que tienen lugar, naturalmente, en una sociedad. Por ello, entendemos que un marco normativo que dé soluciones ex ante y de manera abstracta al conflicto de intereses que aquí se predica es absolutamente necesario, dejando la tarea de concretar las soluciones de los casos que se atisben a los encargados de interpretar y aplicar el ordenamiento jurídico. En esta línea, entendemos necesario plasmar las soluciones que hemos comentado con respecto al velo no integral, positivamente, y al velo integral, negativamente, y ello máxime por tratase de una cuestión en la que cada cual la interpreta de manera distinta, según sea más o menos conservador, por lo que, a la postre, sin lugar a dudas, la calidad de la seguridad jurídica se ve disminuida. Esta disminución de la seguridad jurídica acaba manifestándose por cuanto que, al no haber Ley que regule el asunto, los conflictos nacen, precisamente, por saltarse la reserva de ley exigida constitucionalmente. Con ello no solo hacemos referencia a la Ordenanza de Lleida, sino también a aquellos otros casos en los que es un Instituto el que decide qué solución tomar ${ }^{85}$. Esto provoca una falta de homogeneidad en las soluciones que, como decimos, atenta contra la seguridad jurídica, lo cual solamente podría solucionarse con una norma emanada de las Cortes Generales. En este sentido, el 23 de julio de 2010 el Senado instó al Congreso a prohibir el uso

${ }^{84}$ FERREIRO GALGUERA, J., "El burka, la sancion y la persuasion», Diario El Pais, 18/06/2010. Vid., también el interesante capítulo del profesor FERREIRO GALGUERA, J., "Símbolos religiosos en la escuela pública», en SOUTO PAZ, J., Educación y libertad, 2012, pp. 81-26. A esto añade el razonamiento siguiente: «No podemos desvincular esas prendas de lugares como Afganistán o Chechenia donde, por ser obligatorio, su uso enmascara una condición de esclavitud o al menos de sumisión. No obstante, multar o sancionar a la mujer que porta en la calle un burka o un niqab podría acarrear, además, efectos perniciosos. En primer lugar, en el supuesto que la mujer lo lleve por imposición, se estaría castigando no al verdugo sino a la víctima. En segundo lugar, la multa o sanción le generaría un miedo y una desconfianza que le induciría a replegarse en su ámbito doméstico, donde presumiblemente no respiraría un ambiente de libertad, cegando así su único puente hacia la integración. En tercer lugar, la prohibición no asimilada podría generar un efecto dominó, de modo que en vez de acabar con la decena de casos que debe haber en España los podría multiplicar en poco tiempo».

${ }^{85}$ De manera similar opina MORENO ANTÓN, M., en «Hiyab y escuela en España: un supuesto de gestión excluyente de la diversidad», op. cit.

(C) UNED. Revista de Derecho UNED, núm. 23, 2018 
del burka en los espacios públicos. Mientras, el Gobierno se planteaba presentar un proyecto de ley sobre libertad religiosa que tendría como principal finalidad limitar el uso del velo en los espacios públicos y regular la presencia de símbolos religiosos en edificios públicos (escuelas, hospitales o cárceles). En un frente abierto en el que el Partido Socialista afirmó que su uso es incompatible con la dignidad del ser humano y el Partido Popular sostuvo que atenta contra la igualdad, las opciones de una posible regulación general son obvias. Incluso el Ministro de Justicia abogó, sin ambages, por regular el uso del burka o niqab "para defender la dignidad de las mujeres $y$, especialmente, por razones de seguridad». Por el momento, el horizonte normativo es confuso y nada indica que vayan a realizarse cambios inminentes en la regulación por Ley Orgánica del derecho a la libertad religiosa. Es suficientemente elocuente el hecho de que, habiéndose planteado en sede parlamentaria (Senado) una moción instando al Gobierno «a realizar las reformas legales y reglamentarias necesarias para prohibir el uso en espacios o acontecimientos públicos que no tengan una finalidad estrictamente religiosa, de vestimentas o accesorios en el atuendo que provoquen que el rostro quede completamente cubierto y dificulten así la identificación y la comunicación visual, al suponer esa práctica una discriminación contraria a la dignidad de las personas y lesivas de la igualdad real y efectiva de los hombres y mujeres ${ }^{86}$, aprobada en sesión de 23 de junio de 2010, nuestro legislativo nacional no haya adoptado la solución solicitada.

En nuestra opinión, la inacción del Estado no es una respuesta válida; no nos sirve. El Estado tiene la obligación de prevenir y proteger contra aquellas prácticas que lesionen a las mujeres acudiendo a la capacitación, a medidas legislativas y de sustitución de las prácticas discriminatorias, al diálogo con los dirigentes religiosos... entre otras estrategias, porque cuando se ataca a la mujer en su dignidad, ya no hay lugar ni para la soberanía ni para las especificidades culturales o religiosas.

Acabamos por tanto este estudio con la misma conclusión que realizábamos en nuestra otra contribución a la investigación jurídica sobre el tema ya mencionada anteriormente ${ }^{87}$ : $" E n$ el presente trabajo planteamos la conveniencia de acometer las modificaciones legislativas que sean necesarias en nuestro país para garantizar cuestiones tan básicas e importantes en un Es-

${ }^{86}$ BOCG. Senado. Serie 8 núm. 484, de 21 de junio de 2010.

87 Vid., PAREJO GUZMÁN, M.J., «Resolución de conflictos entre la diversidad religosa y los derechos de las mujeres en España», op. cit., pp. 189-209. 
tado social y democrático de Derecho como es el nuestro tales como el reconocimiento, respeto y protección de la dignidad de la mujer, la igualdad sexual y los derechos y libertades más fundamentales".

\section{BIBLIOGRAFÍA UTILIZADA}

AlCALE, M., La discriminación hacia la mujer por razón de género en el Código Penal, Madrid, 2006, p.68.

ARdila TrujILlo, M.: «Hacia la resolución de los conflictos entre la protección de la diversidad cultural y el reconocimiento de los derechos de las mujeres", Revista Derecho del Estado, $n .^{\circ} 26$, enerojunio, 2011, pp. 137-152.

ARECES PiÑol, M.T.: « ¿El velo integral, burka y niqab, queda amparado por el legítimo ejercicio de la libertad religiosa?», Revista General de Derecho Canónico y Derecho Eclesiástico del Estado, $n .^{\circ} 26$, 2011, p. 36.

BRAMON, D.: Ser mujer y musulmana, Biblioteca del Islam Contemporáneo, España, Bellaterra, 2006, p. 123.

CASTilla VÁzQuez: «Eso No SE HACE, eso no se toca, de eso no se habla. La desigualdad de género en las religiones», Gazeta de Antropología, 2009, 25 (2), artículo 40.

CASTRO Jover, A.: «Inmigración, pluralismo religioso y educación», Laicidad y libertades: escritos jurídicos, $n .^{\circ}$ 2, 2002, pp. 89 a 119.

Combalía Solís, Z.: «¿Igualdad o equidad?: el reconocimiento en occidente de instituciones islámicas de inspiración patriarcal», Igualdad efectiva entre mujeres y hombres: diagnóstico y prospectiva, Atelier, 2009, pp. 21-48.

Contreras Mazarío, J.M, Derecho y Factor Religioso, Valencia, Tirant lo Blanch, 1. ${ }^{\text {a }}$ ed., 2015, p. 17.

CONTRERAS MAZARío, J.M.: «Globalización, derechos humanos y prácticas tradicionales en el ámbito de la familia. Especial referencia a las actividades de las Naciones Unidas», Globalización y Derecho, Editorial Colex, Madrid, 2003.

FERNÁNDEZ-CoRONADO GONZÁLEZ, A.: «Matrimonio islámico, orden público y función promocional de los derechos fundamentales», Revista Española de Derecho Constitucional, 29, $n .^{\circ} 85,2009$, pp. 125-156. 
Ferreiro Galguera, J., «El burka, la sancion y la persuasion», Diario El País, 18/06/2010.

Ferreiro Galguera, J., «Símbolos religiosos en la escuela pública», en Souto PaZ, J., Educación y libertad, 2012, pp. 81-26.

GARCía RuIz, Y.: «Pluralidad religiosa, diversidad cultural y derechos de la mujer: Novedades jurisprudenciales en España», Gestión de la diversidad cultural en las sociedades contemporáneas, Directores M. ${ }^{a}$ Teresa Regueiro García y Salvador Pérez Álvarez, Tirant lo Blanch, Valencia, 2014, pp. 325-348.

GARCía VÁzQUEZ, S., El derecho a la libertad religiosa y el uso del velo islámico. Marco constitucional, normativo y Jurisprudencial, 2013, p. 394.

JoRdÁn VILLACAMPa, M.L.: «Religión y derecho en la España de la primera década del tercer milenio», Ilu. Revista de Ciencias de las religiones, Anejos, XI, 2004, pp. 41 a 50.

LÓPEZ-SidRo LÓPEZ, Á. «Restricciones al velo integral en Europa y en España: la pugna legislativa para prohibir un símbolo», Revista General de Derecho Canónico y Derecho Eclesiástico del Estado, 32, 2013, p. 2.

LÓPEZ-SidRo LóPEZ, Á., «La libertad de expresión de la jerarquía eclesiástica y el discurso del odio", Revista General de Derecho Canónico y Derecho Eclesiástico del Estado, número 42, octubre 2016, p. 8.

MARía Morán, G., «La igualdad religiosa y la mujer en las iglesias cristianas: su incorporación jurídica a las órdenes sagradas», Stato, Chiese e pluralismo confessionale. Rivista telematica (www. statoechiese.it), 2015, p. 4.

Martínez-Torrón, J., La igualdad de sexos en el sistema acordado de relaciones entre Estado español y confesiones religiosas. [online] Aequalitas: Revista jurídica de igualdad de oportunidades entre mujeres y hombres, 2012, pp. 63-65.

Moreno ANTón, M., «Hiyab y escuela en España: un supuesto de gestión excluyente de la diversidad», Revista latinoamericana de Derecho y religión, Vol. 2, núm. 1, 2016, pp. 1.-25.

Muñoz Conde, F. y García Arán, M., Derecho penal, parte general, Tiran lo Blanch, Valencia, 9. ${ }^{\text {a }}$ ed., 2015, pp. 79-80.

NASSIRI SEDIRI, 2014. La realidad de la mujer en el islam. Tesis de máster, María Socorro Suárez Lafuente (dic). 
PAREJo GuZMán, M.J., «Resolución de conflictos entre la diversidad religiosa y los derechos de las mujeres en España», Laicidad y Libertades. Escritos Jurídicos, n. 15, 2015, pp. 189-209.

RUEDa MARTín, M.A., La violencia sobre la mujer en su relación de pareja con un hombre, Ed. Reus, Madrid, 2012, p. 51.

Salazar Benítez, O., La autonomía relacional de las mujeres como límite de la diversidad cultural y religiosa: A propósito de la polémica prohibición del velo integral, 2015, pp. 28 y ss.

SuÁrez Pertierra, G.: «Individuo, grupos, confesiones en el sistema democrático español», Religión, religiones, identidad, identidades, minorías: actas del V Simposio de la Sociedad Española de Ciencias de las Religiones, Coord. Fernando Amérigo, Valencia 1-3 de febrero de 2003, SECR, pp. 7-24.

Souto Galván, B., "Discurso del odio: Género y libertad religiosa», Revista General de Derecho Penal, 23, 2015, p. 3.

SALVATIERRa Ossorio, A. Esposas y madres, la mujer en el judaísmo clásico, año 54, n. ${ }^{\circ}$ 913, 2004, pp. 26-31.

S. CatalÁ, «Libertad religiosa de la mujer musulmana en el islam y uso del velo», en A. Motilla DE La CALle (coord.), El pañuelo islámico en Europa, Marcial Pons, Madrid, 2009.

VÁzQuez Gómez, R., «Aproximación al derecho islámico y su regulación del velo», en Ius Canonicum, 94, 2007, p. 611. 
